\title{
Characterisation of Titanium Dental Implants. II: Local Biomechanical Model
}

\author{
Stig Hansson ${ }^{*}$, , Johanna Löberg ${ }^{1,2}$, Ingela Mattisson ${ }^{1}$, Elisabet Ahlberg ${ }^{2}$ \\ ${ }^{1}$ Astra Tech AB, SE-431 21 Mölndal, Sweden \\ ${ }^{2}$ Department of Chemistry, University of Gothenburg, SE-41296 Gothenburg, Sweden
}

\begin{abstract}
A theoretical model for estimation of the bone-to-implant interfacial shear strength induced by implant surface roughness has been developed. Two different assumptions regarding the constitutive behaviour of the interfacial bone were made. 1) The bone exhibits an ideally plastic deformation - the plastic mode. 2) The bone exhibits a linearly elastic deformation - the elastic mode. In the plastic mode it was found that the estimated interfacial shear strength was directly proportional to the 2D surface roughness parameter mean slope. For the elastic mode a new $2 \mathrm{D}$ surface roughness parameter was defined. With this parameter a direct proportionality between parameter value and estimated interfacial shear strength was also obtained in the elastic mode. The model was extended into 3D mode. The model was used to evaluate topographies of implant surfaces. The calculated results showed a similar trend to interfacial shear strength results reported in vivo.
\end{abstract}

Keywords: Interfacial shear strength, titanium dental implants, biomechanics, surface roughness parameters, mean slope.

\section{INTRODUCTION}

Dental implants are subjected to significant functional forces [1]. These forces are transmitted to the surrounding bone as compressive forces, shear forces and tensile forces at the implant-bone interface. The higher the ability of the interface to withstand these three types of forces the bigger the loads the implant can support. The ability of the interface to resist compressive forces is substantial [2] in comparison to the capacity to stand tensile forces even though some attempts have been made to enhance the latter [3-5]. Much research has been spent on trying to enhance the bone implant interfacial shear strength through modification of the roughness of the implant surface. A typical design of this kind of studies has been as follows. Implants have been inserted in a bone. After a certain healing time the torque required to remove the implants have been registered. With knowledge of the area of the implant surface in contact with the bone and the distance between this surface and the longitudinal axis of the implant the interfacial shear strength can be calculated. In many of these studies the interfacial shear strength has not been calculated explicitly but since there is a directly proportional relationship between removal torque and interfacial shear strength, the interfacial shear strength has indirectly been studied. The results obtained in vivo have been correlated to the values of different surface roughness parameters [6-13]. Wennerberg and Albrektsson [14], suggested that the surface topography be characterized by at least one height, one space, and one hybrid parameter. However the characterisation of surface roughness by means of surface roughness parameters has been called in question since topographically very different surfaces can have the same values of a number of roughness parameters [15]. However, a

*Address correspondence to this author at the Astra Tech AB, SE-431 21 Mölndal, Sweden; Tel: +46 3177630 00; Fax: +46 3136683 80;

E-mail: Stig.Hansson@astratech.com study showed that by using complementary techniques and surface parameters, surfaces with similar topographies can be separated [16]. An evaluation regarding different surface roughness parameters' validity for describing dental implant surfaces can be found elsewhere [16]. In a theoretical study Hansson [17], found no uniform correlation between the values of a number of surface roughness parameters and estimated interfacial shear strength. Under the assumption that a rough implant surface can be conceptualized as consisting of pits Hansson and Norton [18], in another theoretical study, found that the interfacial shear strength increased with pit size and pit packing density. The shape of the pits was also found to influence the interfacial shear strength, the half-spherical shape being the most effective one. An obvious shortcoming of this study is that the effect of protrusions on the surface was neglected.

One aim of the present study was to, by use of solid mechanics, identify, and/or develop surface roughness parameters which on theoretical grounds can be expected to exhibit correlation with bone-implant interfacial shear strength and apply these parameters on a number of experimental surfaces. Another aim was to develop a method by means of which the ability of a rough surface to induce interfacial shear strength can be estimated.

\section{DEVELOPMENT OF A LOCAL BIOMECHANICAL MODEL}

In the development of a theoretical model reflecting the mechanical behaviour of the implant-bone interface the composition of the interfacial bone and its mechanical properties must be considered.

\subsection{The Nature of the Interfacial Bone}

Of major importance for the bone-implant interfacial shear strength is the property of the bone immediately adjacent to the implant surface. Several studies of this 
interface on an ultrastructural level have been published but the results are unfortunately not fully consistent. In some studies a thin zone completely lacking collagen and/or mineral has been found immediately adjacent to the implant surface [19-29]. Other studies report reduced levels of collagen and/or mineral at the implant surface [30-34].

The effect of mechanical stimulation of bone tissue, within physiological limits, is anabolic; on the tissue level [35-40], on the cellular level [41-43] and on the molecular level [44]. A surface roughness will bring about a mechanical interaction between implant and bone on a microscopic level. This mechanical stimulation can be expected to have an anabolic effect on the interfacial bone increasing the bone strength. Surface topography has also been found to affect cellular responses such as differentiation, proliferation, and behaviour [45-47]. However such a dynamic effect is not considered in this study, instead a static situation is assumed.

\subsection{The Mechanics of the Implant-Bone Interface}

Bone consists of collagen, mineral, ground substance and a small amount of non-collagenous proteins. The mechanical strength of bone depends on its content of collagen and mineral [48-51]. Young [51] suggested that collagen gives bone its tensile strength and mineral its compressive strength. The ground substance of bone is probably viscous [51, 52]. A consequence of the reduced levels of collagen and/or mineral immediately adjacent to the implant surface is that the strength of bone is reduced in the interface region. How much it is reduced is not known.

For the establishment of a mathematical model mirroring the mechanical behaviour of the implant-bone interface the following assumptions were made:

1. The bone is a continuum material and the bone-toimplant contact is $100 \%$.

2. The bone has a uniform compressive strength, $\sigma_{\text {bcf }}$, and uniform shear strength, $\tau_{\mathrm{bf}}$, within a zone containing the surface roughness. Since the bone strength probably increases with increasing distance from the implant surface [18], the assumed values of these entities should probably increase with increasing dimensions of the roughness.

3. The surface roughness is conceptualised as consisting of pits [18] and of protrusions.

4. The interfacial shear strength is brought about by interlocking. Bone grows into the pits in the implant surface and creates retention. In the same way roughness asperities protrude into the bone and create retention. The retention is brought about by compressive forces between roughness elements and bone. The adhesion strength and friction between surface elements and bone are zero. The rational of assuming zero friction comes from the fact that the contribution to bone-implant interfacial shear strength caused by interlocking between the asperities of surface roughness and bone is in focus. By assuming a certain coefficient of friction the effect of friction can be superimposed on the interfacial shear strength caused by interlocking.
5. For occasional protrusions of the roughness into the bone, the failure mode is compressive fracture of the bone; the surface protrusions are assumed not to yield (Fig. 1). Assuming a width of $\Delta y$ for a protrusion fracture due to compression occurs when the compressive force, $\mathrm{F}_{\mathrm{c}}$, reaches:

$$
\mathrm{F}_{\mathrm{c}}=\frac{\sigma_{\mathrm{bcf}} \Delta \mathrm{x} \Delta \mathrm{y}}{\cos \alpha}
$$

For more densely packed protrusions the spaces between them should be regarded as pits - see below.

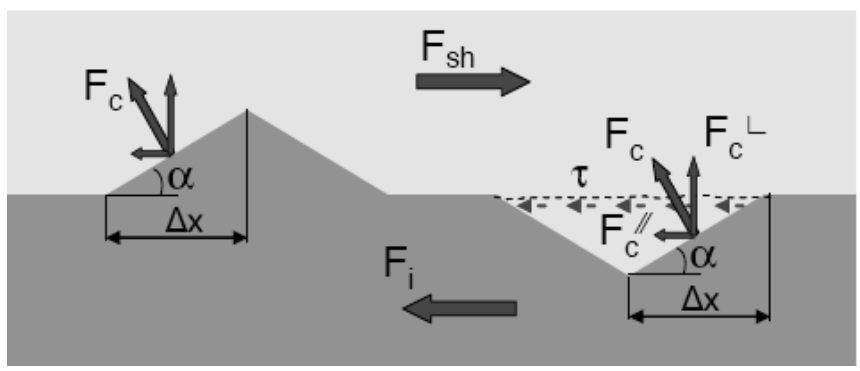

Fig. (1). For an occasional protrusion, failure occurs by compression. For a pit, failure either occurs through compression or through shear depending on the geometry of the pit.

6. For bone plugs protruding into the pits the failure mechanism will either be shear fracture or compressive fracture of the bone depending on the relationship between bone shear strength and bone compressive strength and on the geometry of the pit. Also in this case the material constituting the surface roughness is assumed not to yield. Assuming a width of $\Delta y$ for the pit in Fig. (1), shear fracture occurs when the shear force reaches:

$\mathrm{F}_{\mathrm{sh}}=\tau_{\mathrm{bf}} 2 \Delta \mathrm{x} \Delta \mathrm{y}$

(Shear strength of bone multiplied by fracture surface area). Compressive fracture occurs when the compressive force $F_{c}$ reaches:

$\mathrm{F}_{\mathrm{c}}=\frac{\sigma_{\mathrm{bcf}} \Delta \mathrm{x} \Delta \mathrm{y}}{\cos \alpha}$

Then the horizontal component of this force, $\mathrm{F}_{\mathrm{c}}$, is:

$$
\mathrm{F}_{\mathrm{c}}^{\prime \prime}=\frac{\sigma_{\mathrm{bcf}} \Delta \mathrm{x} \Delta \mathrm{y} \cdot \sin \alpha}{\cos \alpha}=\sigma_{\mathrm{bcf}} \Delta \mathrm{x} \Delta \mathrm{y} \cdot \tan \alpha
$$

This implies that if the expressions in (5) are fulfilled failure occurs through shear, else failure occurs through compression.

$$
\left(\tau_{b f} 2 \Delta x \Delta y\right)<\left(\sigma_{b c f} \Delta x \Delta y \cdot \tan \alpha\right) \Leftrightarrow \frac{\tau_{b f}}{\sigma_{b c f}}<\frac{\tan \alpha}{2}
$$

In fatigue tests Zioupos et al. [53], found that the relationship between shear and compressive strength of cortical bone varied between one third and one quarter at the same cycle number. This should mean that the shift between compressive and shear fracture occurs when the angle $\alpha$ (Fig. 1) lies between $\arctan (2 / 3)=33.7^{\circ}$ and $\arctan (1 / 2)=$ $26.6^{\circ}$. In the following it is assumed that this relationship also applies to the bone immediately adjacent to the implant 
surface and that the shift between compressive fracture and shear fracture occurs when than angle $\alpha=30^{\circ}$.

Fig. (2) shows a number of random profiles of a surface blasted with $\mathrm{TiO}_{2}$ particles. In Fig. (2), a contour of a synthetic pit with the slope angle of $30^{\circ}$ is inserted. In the profiles of the blasted surface, few surface features can be identified with an angle exceeding $30^{\circ}$. It is evident that in few cases fracture will occur through shear of the bone plugs protruding into the surface roughness. It can be concluded that with surface profiles of this type the predominant failure mode is compression fracture.

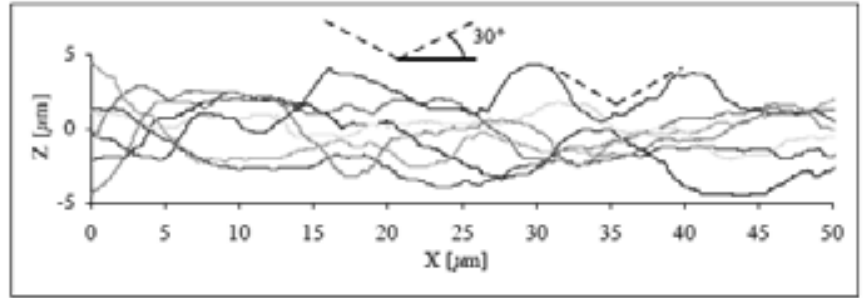

Fig. (2). A number of random profiles of a titanium implant surface blasted with large $\mathrm{TiO}_{2}$ particles. The profiles have been filtered with a $50 \mu \mathrm{m}$ Gaussian filter to remove the form. Only few pits show an angle exceeding $30^{\circ}$ which shows that compressive fracture is the main type of failure occurring on blasted surfaces.

An idealized stress-strain curve for cortical bone shows a linearly elastic phase followed by a plastic phase. Bone exhibits a hierarchical structural organisation and consists of collagen fibres embedded in ground substance impregnated with mineral $[54,55]$. It has been suggested that the elastic high strain rate failures result from fractures in the cement lines constituting the boundaries of the osteons while the plastic low strain rate failures arise from distortion of lamellar substructures resulting in separation and fractures in weaker planes [54]. With high strain rates, the plastic part of the stress-strain curve is short and the smaller the strain rate, the more pronounced is the plastic phase [54]. Thus, considering a case of slow fracture, it seems reasonable to apply theory of plasticity in the derivation of the boneimplant interfacial shear strength which means that all bone at the different fracture surfaces is in the plastic phase. Conversely, in case of rapid fracture, theory of elasticity should be applied implying that all bone at the different fracture surfaces is in the elastic phase. By using both plasticity and elasticity theories, different qualities of the interfacial region are considered.

Consider the situation in Fig. (1). The implant force, $F_{i}$, is transferred to the bone by surface elements inclined in the direction of this load. The load gives rise to compressive forces, $F_{c}$, at these surface elements. These compressive forces have components $\left(\mathrm{F}_{\mathrm{c}}{ }^{\prime \prime}\right)$ in parallel with the implant surface and components $\left(\mathrm{F}_{\mathrm{c}}{ }^{\llcorner}\right)$directed perpendicularly to the implant surface. The latter components will tend to push the bone away from the implant and additionally give rise to equally big but oppositely directed reaction forces which will compress the implant. This will give rise to the formation of a series of small gaps between the implant and the bone (Fig. 3). These gaps will reduce the interlocking effect and reduce the interfacial shear strength. The resistance to this gap formation exerted by the bone depends on the bone anatomy while the resistance exerted by the implant depends on the implant design and the modulus of elasticity of the implant material. The less resistance exerted by the bone and by the implant the bigger the gap. This means that the interfacial shear strength does not only depend on the topography of the roughness and the bone quality but also on the bone anatomy, the implant design and on the modulus of elasticity of the implant material.

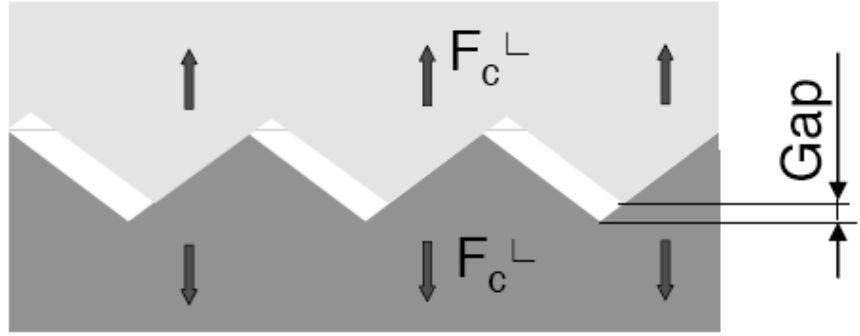

Fig. (3). The compressive forces on the surface elements have components directed perpendicularly $\left(\mathbf{F}_{\mathbf{c}}{ }^{\llcorner}\right)$to the implant surface. These force components together with reaction forces on the implant create a series of gaps between implant and bone.

In this study it is assumed that the resistance to gap formation exerted by the bone and by the implant is so big that no substantial gap arises. This is called the Local Model. In a forthcoming study the more complex situation with a gap formation will be analysed - the Global Model.

\subsection{Theory of Plasticity}

The implant surface roughness is assumed to consist of surface elements which when projected onto a horizontal plane has a length of $\Delta \mathrm{x}$ and a width of $\Delta \mathrm{y}$ whereby $\Delta \mathrm{x}$ and $\Delta y$ is the pixel distance applied by a roughness measurement equipment. When applying theory of plasticity it is assumed that the implant displacement caused by a load is so big that the deformation of all bone in direct contact with the implant, which participates in resisting the implant force, $\mathrm{F}_{\mathrm{i}}$, lies in the plastic region of the stress-strain curve irrespective of slope angle $\alpha$ (Fig. 4).

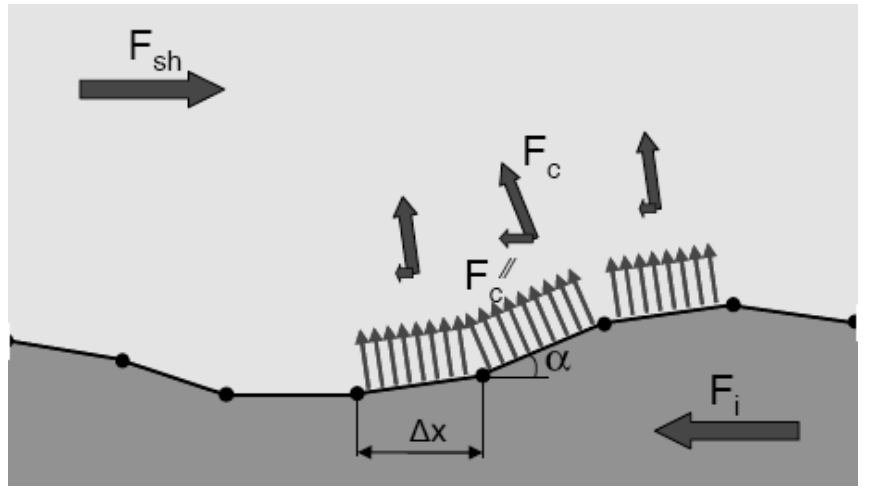

Fig. (4). The force distribution at fracture in the theory of plasticity.

At first, the special case is studied where the slope of all surface elements is parallel with the implant force, $F_{i}$, (Fig. 4). Then the theory is generalized to cover element slopes in any direction. 


\subsubsection{The Slope of the Surface Elements is Aligned with the Implant Force}

The implant force, $\mathrm{F}_{\mathrm{i}}$, is transmitted to the bone by the surface elements which are inclined (angle of inclination = $\alpha$ ) in the same direction as this force (Fig. 4). Due to the zero friction and adhesion the forces, $F_{c}$, exerted on the bone by these surface elements are directed perpendicularly to the respective surface element. The horizontal components $\left(F_{c}{ }^{\prime \prime}\right)$ of these forces are aligned with the implant force $F_{i}$ which equals the sum of all $F_{c}{ }_{c}$. When fracture occurs, the magnitude of all normal stresses at the surface elements in question equals the compressive strength of bone $\left(\sigma_{\mathrm{bcf}}\right)$. The implant force at fracture, $\mathrm{F}_{\mathrm{i}}$, becomes:

$\mathrm{F}_{\mathrm{i}}=\sum \mathrm{F}_{\mathrm{c}}^{\prime \prime}=\sum\left(\sigma_{\mathrm{bcf}} \Delta \mathrm{x} \Delta \mathrm{y} \frac{\sin \alpha}{\cos \alpha}\right)=\sigma_{\text {bcf }} \sum(\Delta \mathrm{x} \Delta \mathrm{y} \cdot \tan \alpha)$

\subsubsection{The Slope of the Surface Elements is Not Aligned with the Implant Force}

Consider the situation in Fig. (5). The direction of the implant force, $\mathrm{F}_{\mathrm{i}}$, forms an angle $\beta$ with the direction of the slope. At fracture the compressive force, $F_{c}$, of the surface element in question is expressed by equation (3):

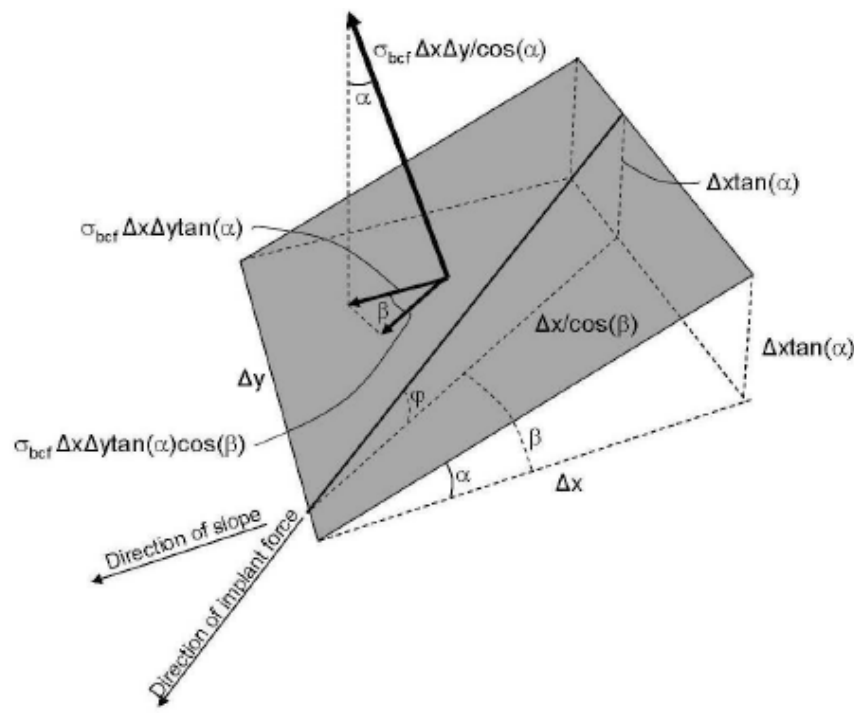

Fig. (5). Schematic showing a case where the slope of the surface element is not aligned with the implant force $\mathrm{F}_{\mathrm{i}}$.

The component of this force which is aligned with the implant force, $\mathrm{F}_{\mathrm{i}}$, is:

$\sigma_{\mathrm{bcf}} \Delta \mathrm{x} \Delta \mathrm{y} \cdot \tan (\alpha) \cos (\beta)$

If instead formula (6) is applied $\tan (\alpha)$ shall be substituted by $\tan (\varphi)$ which equals $\tan (\alpha) \cos (\beta)$. The implant force at fracture, $F_{i}$, becomes:

$\mathrm{F}_{\mathrm{i}}=\sigma_{\mathrm{bcf}} \Delta \mathrm{x} \Delta \mathrm{y} \cdot \tan \varphi=\sigma_{\mathrm{bcf}} \Delta \mathrm{x} \Delta \mathrm{y} \cdot \tan (\alpha) \cos (\beta)$

which agrees with expression (7). Thus formula (6) has a general validity; it is valid irrespective of the directions of the slope of the different surface elements.

\subsubsection{The 2D Surface Roughness Parameter Mean Slope is a Predictor of Interfacial Shear Strength}

Consider a longitudinal section with the width $\Delta y$ and the roughness profile shown in Fig. (6). When the implant is moved to the right, the fracture force is obtained by formula (6).

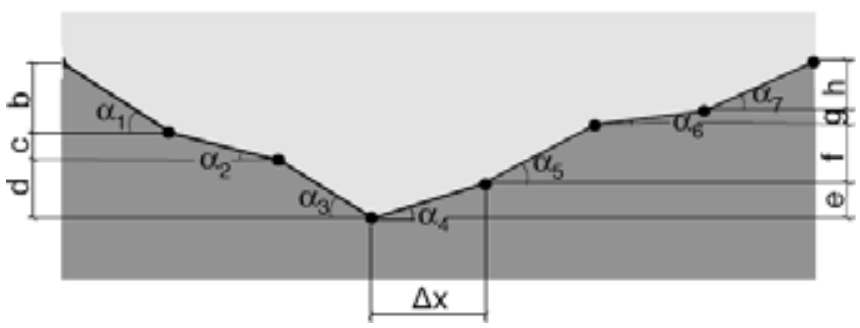

Fig. (6). surface profile used to derive the $2 \mathrm{D}$ mean slope parameter, $\mathrm{R}_{\mathrm{sl}}$.

$$
\begin{aligned}
& F_{i}=\sigma_{b c f} \sum(\Delta x \Delta y \cdot \tan \alpha) \\
& =\sigma_{b c f}\left[\Delta x \Delta y\left(\frac{b}{\Delta x}+\frac{c}{\Delta x}+\frac{d}{\Delta x}\right)\right] \\
& =\sigma_{b c f}[\Delta y \cdot(b+c+d)]
\end{aligned}
$$

When the implant instead is moved to the left, the fracture force becomes:

$$
F_{i}=\sigma_{b c f} \sum(\Delta x \Delta y \cdot \tan \alpha)=\sigma_{b c f} \Delta y(e+f+g+h)
$$

It is obvious that $(b+c+d)=(e+f+g+h)$ which means that the shear strength is equal in both directions (Fig. 6). The interfacial shear strength according to theory of plasticity [56], $\mathrm{I}_{\mathrm{sh}}{ }^{\mathrm{p}}$ is

$$
I_{s h}^{p}=\frac{F_{i}}{7 \Delta x \Delta y}=\frac{\sigma_{b c f} \Delta y(b+c+d)}{7 \Delta x \Delta y}=\frac{\sigma_{b c f}(b+c+d)}{7 \Delta x}
$$

Since $(b+c+d+e+f+g+h) /(7 \Delta x)$ is the $2 D$ surface roughness parameter mean slope $\left(\mathrm{R}_{\mathrm{sl}}\right)$ and since $(\mathrm{b}+\mathrm{c}+\mathrm{d})=$ $(\mathrm{e}+\mathrm{f}+\mathrm{g}+\mathrm{h})$ the following formula can be set up

$$
I_{s h}^{p}=\frac{\sigma_{b c f} R_{s l}}{2}
$$

Thus, when the compressive strength of bone sets the limit for the bone-implant interfacial shear strength and when theory of plasticity is applied, the 2D parameter mean slope seems to be an excellent predictor of interfacial shear strength.

\subsubsection{Application of the 3D Surface Roughness Parameter Mean Slope $-S_{s l}$}

Since the resistance to shear strength is direction specific a generalization to $3 \mathrm{D}$ perspective requires that the roughness is isotropic. Furthermore a definition of a "3D mean slope" parameter is required. Two alternative definitions will be discussed;

1. The 3D mean slope is the average of the absolute maximum slope at all measurement points (orthogonally to the contour line) of the surface $-\mathrm{S}_{\mathrm{sl}}^{1}$ 
2. The $3 \mathrm{D}$ mean slope is the average of the absolute slope in $\mathrm{x}$ and $\mathrm{y}$ directions at all measurement points $\mathrm{S}_{\mathrm{s} 1}^{2}$.

This indicates that the surface roughness parameter rootmean-square of the surface slope, $S_{\mathrm{dq}}$, can be used to get a rough estimate of the interfacial shear strength since this parameter describes the same property as the mean slope parameters.

\subsubsection{Application of the $S^{1}{ }_{s l}$ Definition of 3D Mean Slope}

Considering formulae (4), (6) and (8) it is evident that the resistance exerted by a surface element is the compressive strength of bone multiplied by the area of the surface element projected onto a plane oriented at right angle to the implant force $F_{i}$. Consider a roughness feature which has the shape of a right circular cone (Fig. 7). It should be observed that this roughness feature is isotropic. The area of the cone projected onto such a plane is $\mathrm{D}^{2} \tan (\alpha) / 4$. Consequently the resistance exerted by the cone at fracture is $\sigma_{\mathrm{bcf}} \mathrm{D}^{2} \tan (\alpha) / 4$. The 3D mean slope, $\mathrm{S}_{\mathrm{sl}}^{1}$, in the circular area occupied by the cone is $\tan (\alpha)$. The area occupied by the cone is $\pi \mathrm{D}^{2} / 4$. This gives the following expression for average interfacial shear strength for the surface area occupied by the cone.

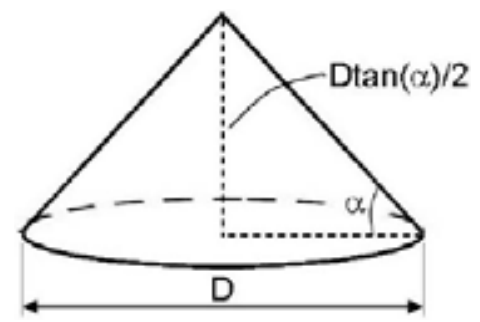

Fig. (7). A right circular cone representing the isotropic 3D slope.

$$
I_{s h}^{p}=\frac{\sigma_{b c f} D^{2}\left(\frac{\tan \alpha}{4}\right)}{\frac{\pi D^{2}}{4}}=\frac{\sigma_{b c f} \tan \alpha}{\pi}=\frac{\sigma_{b c f} S_{s l}^{1}}{\pi}
$$

It is suggested that $\sigma_{\mathrm{bcf}} \mathrm{S}_{\mathrm{sl}}^{1} / \pi$ gives a good estimate of the interfacial shear strength induced by isotropic surface roughness. The assumption of isotropic surface roughness applies particularly for blasted and etched surfaces, which are common on dental implants [16].

\subsubsection{Application of the $S^{2}$ sl Definition of 3D Mean Slope}

The assumption of isotropy means that the parameter $\mathrm{S}_{\mathrm{sl}}^{2}$ can be expressed as follows:

$S_{s l}^{2}=\frac{1}{m n} \sum_{i=1}^{m} \sum_{j=1}^{n}\left[\tan \left(\alpha_{i, j}\right)\right]$

where the slope angle $\alpha_{i, j}$ is defined in Fig. (8). In analogy with the 2D case (Formula 12) the expression for interfacial shear strength becomes

$I_{s h}^{p}=\frac{\sigma_{b c f} S_{s l}^{2}}{2}$

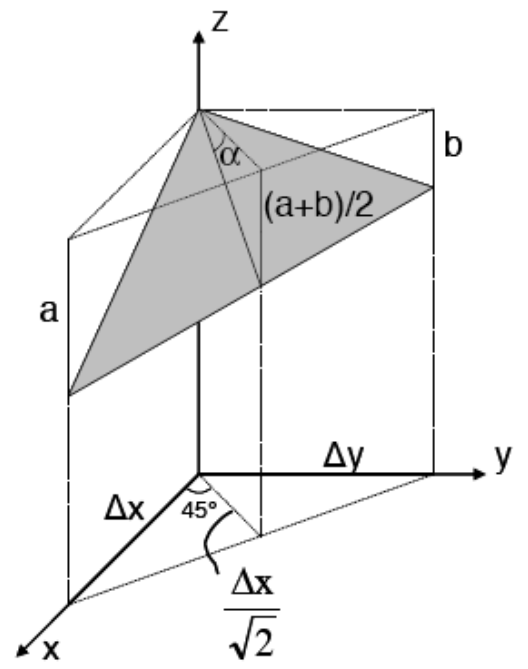

Fig. (8). Schematic used to derive the angle $\alpha$. Assumed $\Delta x=\Delta y$, $\alpha=\arctan \left(\frac{a+b}{\Delta x \sqrt{2}}\right)$.

\subsubsection{Surface Roughness for which Both Shear Fracture and Compressive Fracture can be Expected to Occur}

Consider a surface roughness where a part of the surface area exhibits pits with slope angles exceeding $30^{\circ}$. It was found above that for such pits shear fracture of the bone plugs protruding into the pits can be expected. Assume that the total surface area considered is $A$ and that the area occupied by pits with slope angles exceeding $30^{\circ}$ is $\mathrm{A}_{\mathrm{sh}}$. Then the 2D and 3D interfacial shear strength is given by expressions (16) and (17) respectively.

$I_{s h}^{p}=\frac{\tau_{b f} A_{s h}+\left(\frac{\sigma_{b c f} R_{s l}}{2}\right)\left(A-A_{s h}\right)}{A}$

$I_{s h}^{p}=\frac{\tau_{b f} A_{s h}+\left(\frac{\sigma_{b c f} S_{s l}^{2}}{\pi}\right)\left(A-A_{s h}\right)}{A}$

\subsection{Theory of Elasticity}

It was established above that in case of rapid fracture, theory of elasticity should be applied when estimating the bone-implant interfacial shear strength. This means that there is a direct proportionality between stress and strain for the bone in contact with the implant which resists the implant force, $F_{i}$. Consider the surface profile in Fig. (9a). The implant force $F_{i}$ is assumed to displace the implant by the distance $\mathrm{k}_{1}$ (Fig. 9b). This means that the bone in contact with the vertical part of the profile undergoes this compression. It is further assumed that this compression corresponds to the upper end of the elastic phase of the stress-strain curve where further compression results in fracture. The compression of bone in contact with a surface element with the inclination $\alpha$ (Fig. 9b) amounts to $\mathrm{k}_{1} \sin (\alpha)$. This means that the compressive stress on the surface element can be expressed as follows:

$\sigma_{b c f} \frac{k_{1} \sin \alpha}{k_{1}}=\sigma_{b c f} \sin \alpha$ 


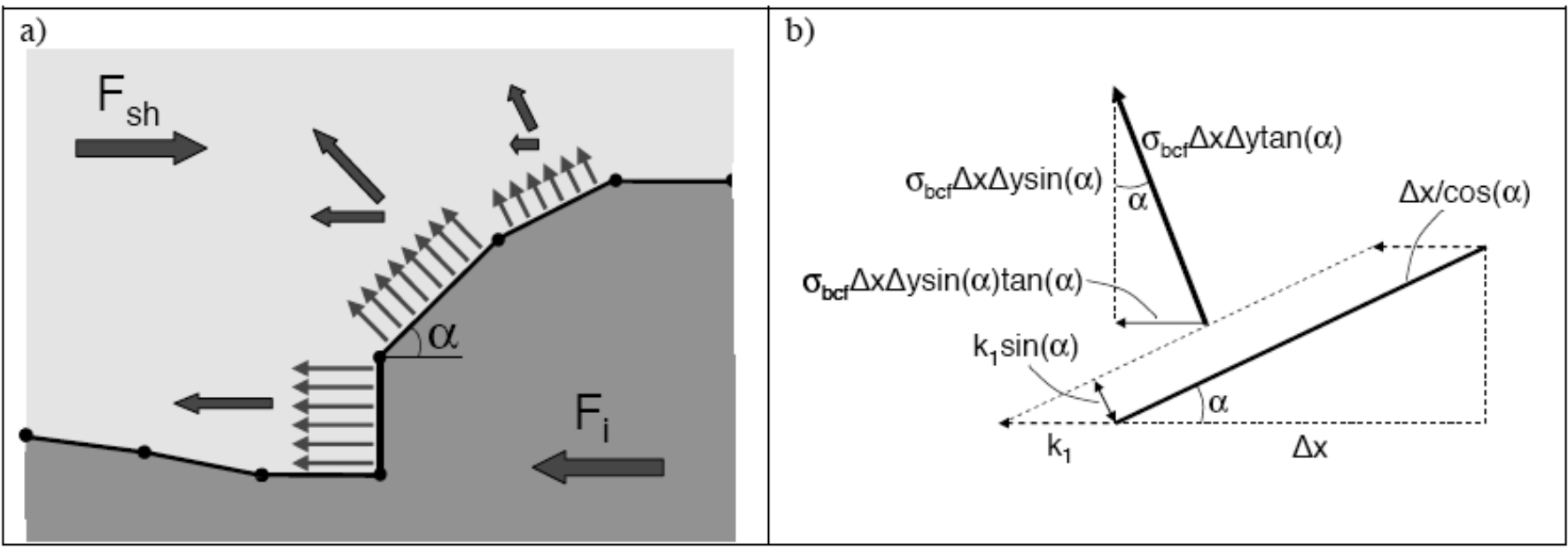

Fig. (9). a) The force distribution at fracture in the theory of elasticity. b) A compression of the bone of $k_{l}$ is assumed to correspond to the upper end of the elastic phase of the stress-strain curve. Further compression is assumed to result in fracture.

The normal force exerted by a surface element becomes:

$\sigma_{b c f} \Delta x \Delta y \frac{\sin \alpha}{\cos \alpha}=\sigma_{b c f} \Delta x \Delta y \tan \alpha$

The horizontal component of this normal force becomes:

$\sigma_{b c f} \Delta x \Delta y \sin \alpha \tan \alpha$

Thus the implant force at fracture equals:

$F_{i}=\sigma_{b c f} \sum(\Delta x \Delta y \cdot \tan \alpha \cdot \sin \alpha)$

where summation is performed over the surface elements the inclination of which is either aligned with the implant force or deviates from this direction by less than $90^{\circ}$. In the above derivation it was assumed that the surface profile exhibits elements where the angle $\alpha=90^{\circ}$ for which the bone compression corresponded to the uppermost part of the elastic phase of the stress-strain curve. Considering cases where the slope of the steepest elements $\left(\alpha_{\max }\right)$ is substantially less than $90^{\circ}$ formula 21 should be corrected for this. In this case the implant force at fracture becomes:

$F_{i}=\sigma_{b c f} \frac{\sum(\Delta x \Delta y \cdot \sin \alpha \cdot \tan \alpha)}{\sin \alpha_{\max }}$

It was found above that the surface roughness parameter mean slope $\left(\mathrm{R}_{\mathrm{sl}}, \mathrm{S}_{\mathrm{sl}}\right)$ perfectly mirrors the interfacial shear strength according to theory of plasticity. In the same way it is possible to define another $2 \mathrm{D}$ surface roughness parameter $\left(R_{\text {ish }}\right)$ which mirrors the interfacial shear strength according to theory of elasticity

$R_{i s h}=\frac{1}{N} \cdot \frac{\sum(\sin \alpha \cdot \tan \alpha)}{\sin \alpha_{\max }}$

where $\mathrm{N}$ is the number of surface elements considered. The equation for interfacial shear strength becomes

$I_{s h}=\frac{\sigma_{b c f} R_{i s h}}{2 \sin \alpha_{\max }}$
A corresponding $3 \mathrm{D}$ surface roughness parameter $\left(S_{\text {ish }}^{2}\right)$ gets the following definition:

$S_{i s h}=\frac{i}{m n \sin \left(\alpha_{\max }\right)} \sum_{i=1}^{m} \sum_{j=1}^{n}\left[\sin \left(\alpha_{i, j}\right) \tan \left(\alpha_{i, j}\right)\right]$

where the slope angle $\alpha_{i, j}$ is defined in Fig. (8). Applying theory of elasticity [57] the theoretical interfacial shear strength for an isotropic surface roughness becomes:

$I_{s h}^{e}=\frac{\sigma_{b c f} S_{i s h}}{2}$

If a part of the surface area exhibits pits with slope angles exceeding $30^{\circ}$, where shear fracture of the bone plugs protruding into the pits can be expected, this can be handled in the same way as above for theory of plasticity.

\section{MATERIALS AND METHODS}

By using the Local calculation model, a measure of the ability of different surface topographies to induce shear strength was obtained and defined by the parameters $S_{\mathrm{sl}}^{2}$ and $\mathrm{S}_{\text {ish }}^{2}$ (defined in the previous section). Using these parameter values and applying the Global model the estimated interfacial shear strength, induced in vivo, will be calculated in a forthcoming paper. Five different experimental surfaces were evaluated: $i$ ) turned surface (TS), ii) TS surface treated with diluted hydrofluoric acid (TS $+\mathrm{HF}$ ), iii) TS surface blasted with small $\mathrm{TiO}_{2}$ particles i.e. fine blasted (FB), representing the surface of the previously commercially available TiOblast ${ }^{\mathrm{TM}}$ implant (AstraTech AB), $i v$ ) TS surface blasted with large $\mathrm{TiO}_{2}$ particles i.e. coarse blasted (CB),v) $\mathrm{CB}$ surface treated with diluted HF-acid (CB+HF), representing the surface of the commercially available dental implant OsseoSpeed ${ }^{\mathrm{TM}}$ (AstraTech AB).

The surface topography was recorded by 3D-SEM (Scanning Electron Microscopy) and AFM (Atomic Force Microscopy). The blasted surfaces were analysed by the SEM technique only at magnifications: $\times 500$ $(247.84 \times 186.24 \mu \mathrm{m}), \times 1200(103.26 \times 77.594 \mu \mathrm{m}), \times 2500$ $(49.569 \times 37.249 \mu \mathrm{m}) \quad(\mathrm{FB}$ surface only), and $\times 5000$ 


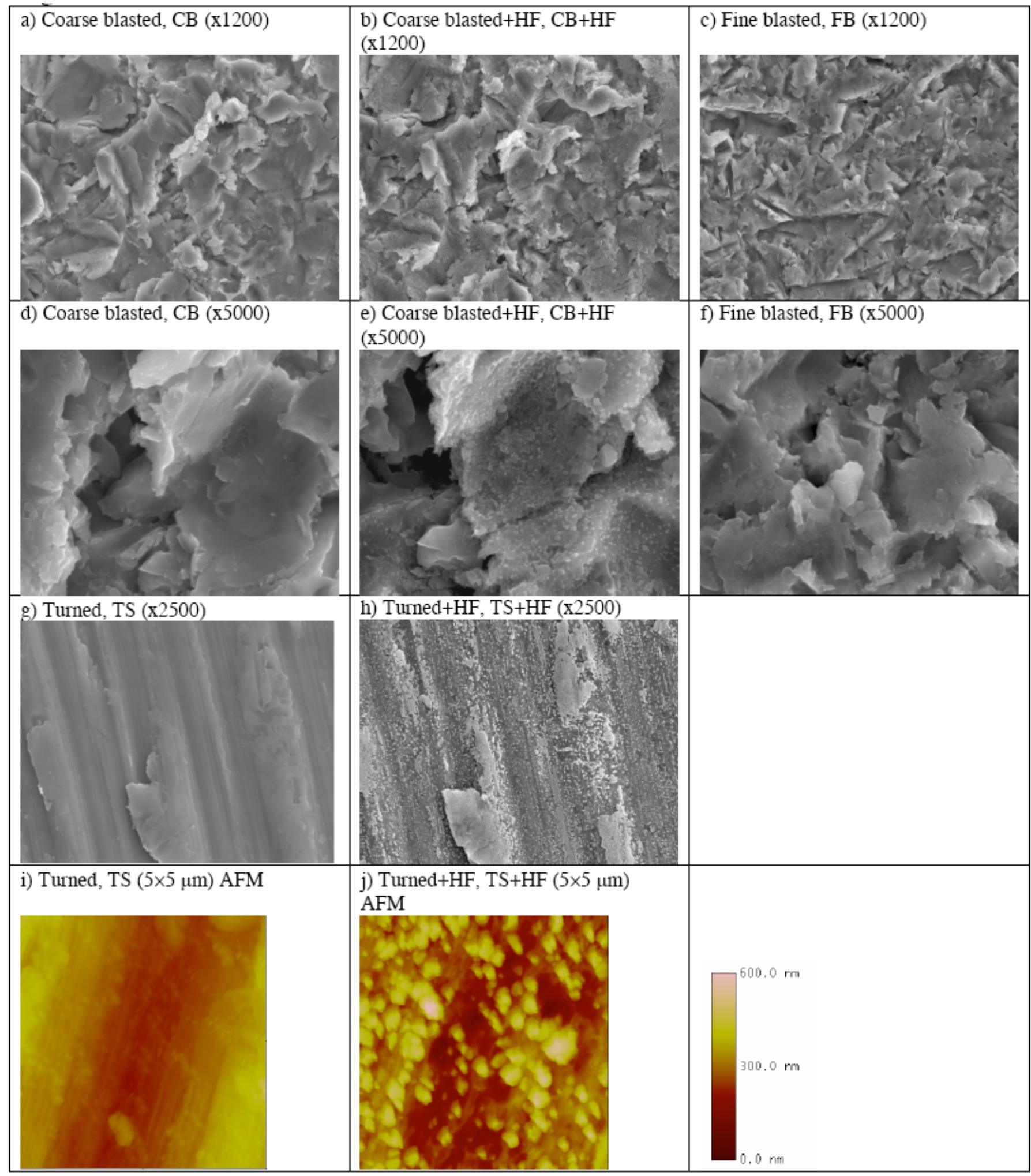

Fig. (10). (a-c) showing SEM images of the blasted surfaces at $\times 1200$ magnification while (d-f) show the same surfaces at $\times 5000$ magnification. $(\mathbf{g}, \mathbf{h})$ show SEM images of the turned and etched surfaces at $\times 2500$ magnification. (i, $\mathbf{j})$ show AFM images of the same surfaces at $5 \times 5 \mu \mathrm{m}$.

$(24.784 \times 18.624 \mu \mathrm{m})$. The turned surfaces were analysed by both AFM and SEM technique, magnifications $\times 500, \times 1200$, $\times 2500$, and $\times 5000$ (the TS+HF surface only). AFM analysis was performed at three different scan sizes: $10 \times 10 \mu \mathrm{m}, 5 \times 5$ $\mu \mathrm{m}$, and $3 \times 3 \mu \mathrm{m}$. Fig. (10) shows images of all analysed experimental surfaces. 3D-SEM analysis of the turned surface on $\times 5000$ magnification was not possible due to limitations in resolution induced by focusing issues. Details regarding the 3D-SEM technique and angles used can be found elsewhere [16]. 


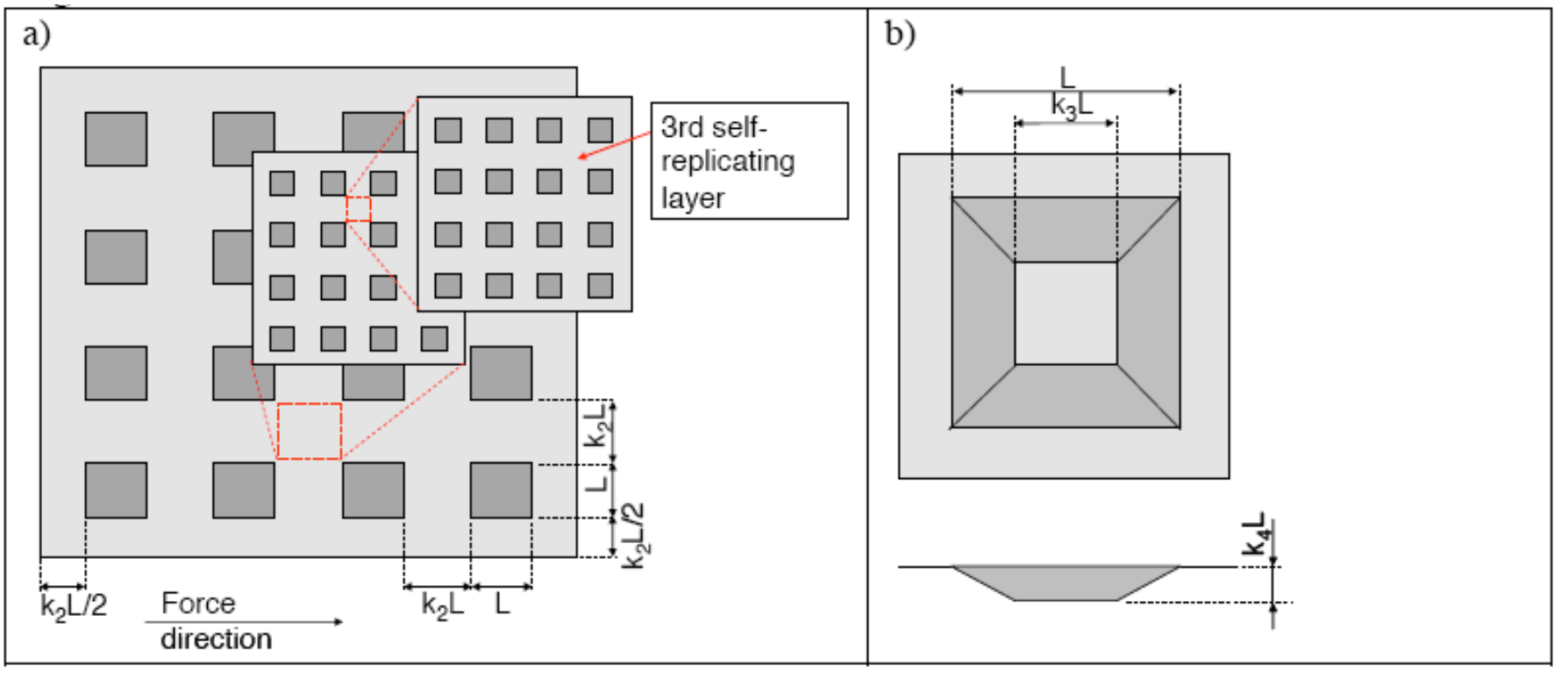

Fig. (11). a) A model surface featuring an array of square pits, arranged in a varying number of self-replicating layers, each consecutive layer being a reduced-size copy of the preceding one. b) The shape of the pits is defined by the coefficients $\mathrm{k}_{3}$ and $\mathrm{k}_{4}$.

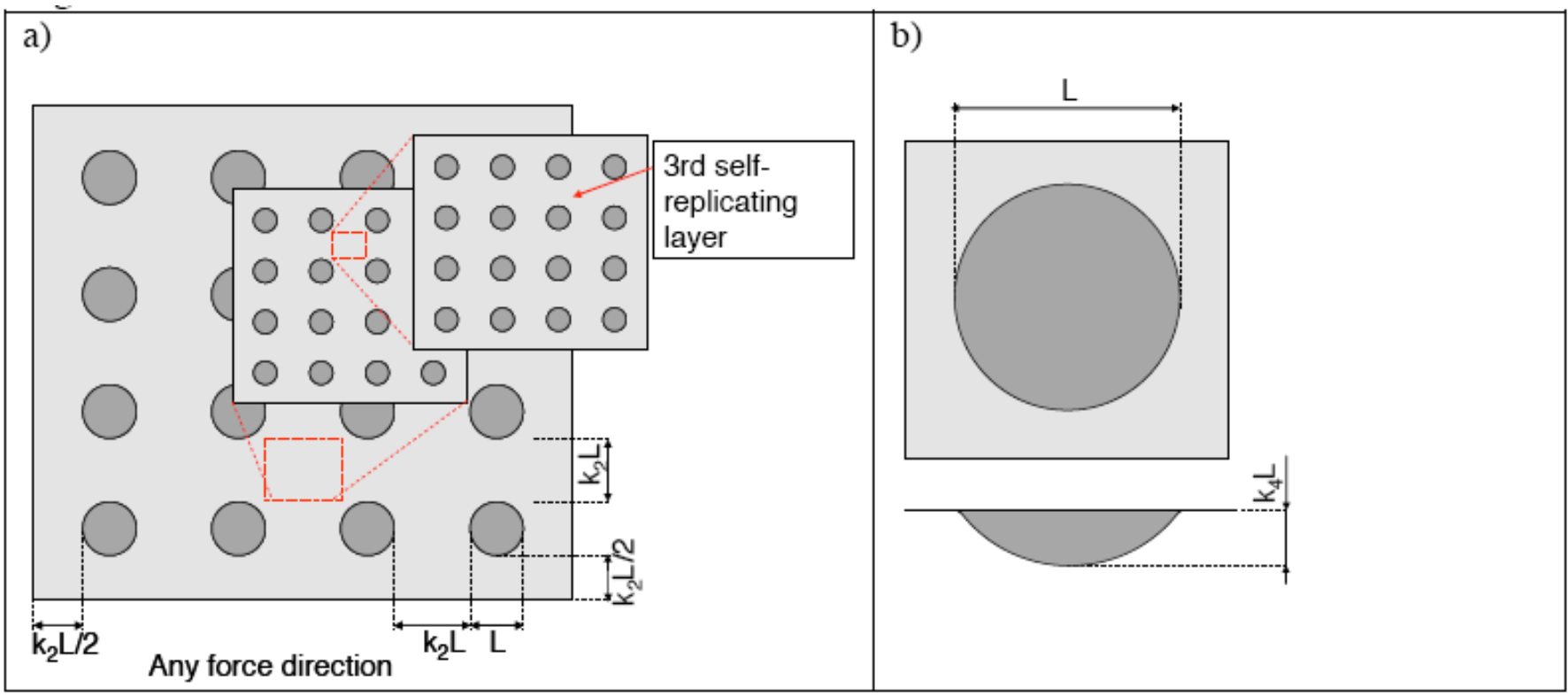

Fig. (12). a) A model surface featuring an array of pits shaped as spherical calottes. b) The shape of the pits is defined by the coefficient $\mathrm{k}_{4}$

All SEM magnifications and AFM scan sizes were imported into the $\mathrm{MeX}^{\circledR}$ [58] software which transforms SEM images into matrixes of numbers from which 3Dmodels are created (more information regarding $\mathrm{MeX}^{\circledR}$ software can be found elsewhere [16]. To enable analysis of how scale changes affect the mean slope parameters, a Gaussian filter of different cut-offs was applied and the sizes used were $20 \%, 15 \%, 10 \%, 5 \%$ of the horizontal width of the 3D-model. The bandwidth of the filter was 100. Scale dependent analysis on the same 3D-models was performed in an earlier analysis where the variable length scale analysis was evaluated and the scale effects on different surface roughness parameters were evaluated [16]. More information regarding the sample preparation and surface characterisation can be found elsewhere [16]. Surface images on all magnifications/scan sizes after the application of the different filter sizes were exported as text files. These text files were used for calculation of the mean slope parameters.

The Local Model calculation program was written in Visual Basic 6.0, Microsoft.

\section{RESULTS AND DISCUSSION}

\subsection{Modelled Surfaces - Effects of Pit Density and Pit Effectivity}

In a theoretical study, where a rough implant surface was conceptualized as consisting of pits, it was found that the interfacial shear strength was the product of the packing density of the pits and the effectivity of the individual pits to serve as retention elements [18]. Similar results were obtained in the present study, by the analysis of model surfaces exhibiting square pits and circular pits with different 
cross sections arranged in self-replicating layers each consecutive layer being a reduced-size copy of the preceding one (Figs. 11, 12). The pit spacing is defined by the coefficient $\mathrm{k}_{2}$ and the cross-sectional shape by the coefficients $\mathrm{k}_{3}$ and $\mathrm{k}_{4}$. The interfacial shear strength of the implant surface depends on how effective the individual pits are as retention elements, expressed by the pit effectivity factor $\left(\mathrm{f}_{\mathrm{pe}}\right)$, and on how densely packed the pits are which is expressed by the pit density $\left(\mathrm{f}_{\mathrm{pd}}\right)$ factor [18]. The values of both these factors can vary between 0 and 1 . The pit density factor is the share of the surface which is occupied by pits. The interfacial shear strength of the implant surface can be expressed in the following way:

$I_{s h}=f_{p e} f_{p d} \tau_{b f}$

Depending on the pit shape the bone plugs protruding into the pits will either be sheared off or compressed to fracture as shown in Fig. (1).

With the same assumption regarding the relationship between shear strength and compressive strength of bone as in Section 2, it was found that in the case of a square pit with a triangular cross section $\left(\mathrm{k}_{3}=0\right)$, the maximum value of 1 for $\mathrm{f}_{\mathrm{pe}}$ was obtained with a pit depth equal to or exceeding $58 \%$ of the pit width while with a rectangular cross section $\left(\mathrm{k}_{3}=1\right)$ the maximum value for $\mathrm{f}_{\mathrm{pe}}$ was achieved already with a depth of $29 \%$ of the pit width. The value of the pit density factor $\left(f_{p d}\right)$ showed a major increase with decreasing value of $k_{2}$ and a minor increase with increasing number of selfreplicating layers.

In the case of circular pits and by applying formula (27) the pit effectivity factor reaches the maximum value 1 when the coefficient $\mathrm{k}_{4}$ amounts to or exceeds 0.34 . The value of the pit density factor $\left(f_{p d}\right)$ showed a major increase with decreasing value of $\mathrm{k}_{2}$ and a minor increase with increasing number of self-replicating layers.

It should be observed that for small values of $\mathrm{k}_{2}$ (both square and circular pits), the assumption underlying the Local model that the material constituting the surface roughness does not yield does no longer hold true. Since, in the case of square pits, the slope of the pit wall resisting the bone was the same for all pits the value of the pit effectivity factor becomes the same for theory of elasticity as for theory of plasticity.

Three theoretical surfaces, consisting of surface features of different densities were created (model A-C, Fig. 13a). The same modelled surfaces were used in a previous study to verify the variable length scale analysis mode used in the present study [16]. The three surfaces where combined to a fourth model (model D) which resembles the real situation of a dental implant surface which often consists of surface features ranging from millimetre to nanometre scale. When altering the surface topography on the macro or micro scale, this often affects the topography on lower scales [59]. Since all sizes of the topography could affect the interfacial shear strength, it is important to analyse and evaluate the shear strength induced by all levels of surface roughness. In the present study, this was accomplished by using complementary techniques, different magnifications/scan sizes, and filters with different sizes. The same analysis method was used and evaluated in a previous study when evaluating scale effects on different surface roughness parameters [16].

The mean slope parameters were calculated by the plasticity theory for all four model surfaces after the application of the different filter sizes as described in Section 3 . The results obtained are presented as a function of $\log$ (filter size $/ \mu \mathrm{m})$ (Fig. 13b). The surface with the lowest pit density (model A), showed the lowest mean slope parameter value while the surface with the highest pit density (model C), showed the highest value. This is in agreement with the findings of Hansson et al. [18] and the present study as discussed above. The combined model (model D), follows the trend of model $\mathrm{C}$ with a higher parameter value at the larger filter sizes, better seen in the inset in Fig. (13b). This increase in mean slope parameter is due to the positive input from the lower density pits of models A and B.

\subsection{Dental Implant Surfaces}

The ability to induce interfacial shear strength of the experimental and dental implant surfaces was calculated by both plasticity and elasticity theory over the whole analysed scale range. The obtained results were plotted against the logarithm of filter size. Applying different techniques, AFM and 3D-SEM, together with the different magnifications/scan sizes and the application of a Gaussian filter of different sizes the mean slope parameter value induced by surface features of heights from $50 \mu \mathrm{m}$ down to $1.5 \mathrm{~nm}$ was calculated.

Discontinuities in mean slope parameter values were obtained with change in magnification and scan size which also was seen for the hybrid parameters $\left(\mathrm{S}_{\mathrm{dr}}, \mathrm{S}_{\mathrm{dq}}\right)$ earlier analysed [16]. The changes were systematic and the trend between the different surfaces was conserved. Due to this, only one magnification or scan size is presented in the following log-log plots. In general, the data presented are obtained from three different spots on the surface sequentially analysed before and after each process step (detailed information in ref [16]). The following sections are structured as follows. The physically modified surfaces (turned and blasted) are evaluated as one group followed by an evaluation of the effect of the chemical treatment of the blasted surface ( $\mathrm{CB}$ and $\mathrm{CB}+\mathrm{HF})$ and of the turned surface (TS and TS+HF). This is followed by a section with some concluding remarks.

\subsubsection{Physical Modifications}

The calculated mean slope parameters of FB, CB, TS, and the $\mathrm{CB}+\mathrm{HF}$ surface, are in Fig. (14) shown as a function of the logarithm of the filter size for $\times 500$ magnification; (a) plasticity theory and (b) elasticity theory. For both theories, a large difference in the mean slope parameters are obtained for the TS, FB, and CB surfaces at the lower SEM magnification (Fig. 14). This is probably due to the larger surface features induced by blasting with larger particle sizes. This can also be seen in the $\mathrm{MeX}^{\circledR}$ depth scale images shown as insets in Fig. (14a). These images show the topography left after the filtration which the mean slope parameter is calculated on. The images show that the fine blasted surface (FB) consists of smaller surface features than the coarse blasted surface (CB) which is in agreement with the higher amplitude parameter values obtained for the $\mathrm{CB}$ 
(a)

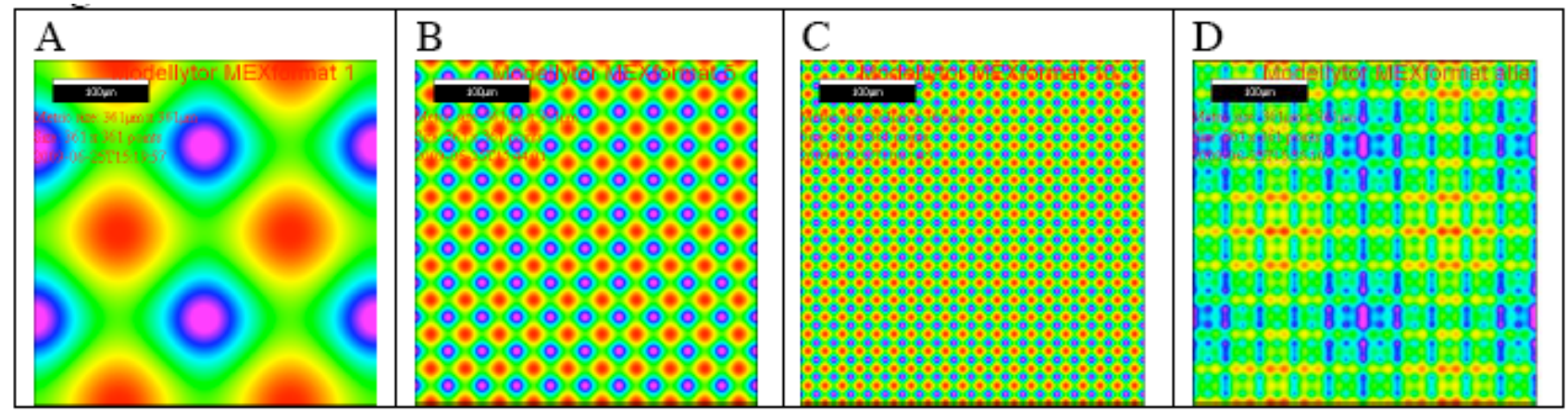

(b)

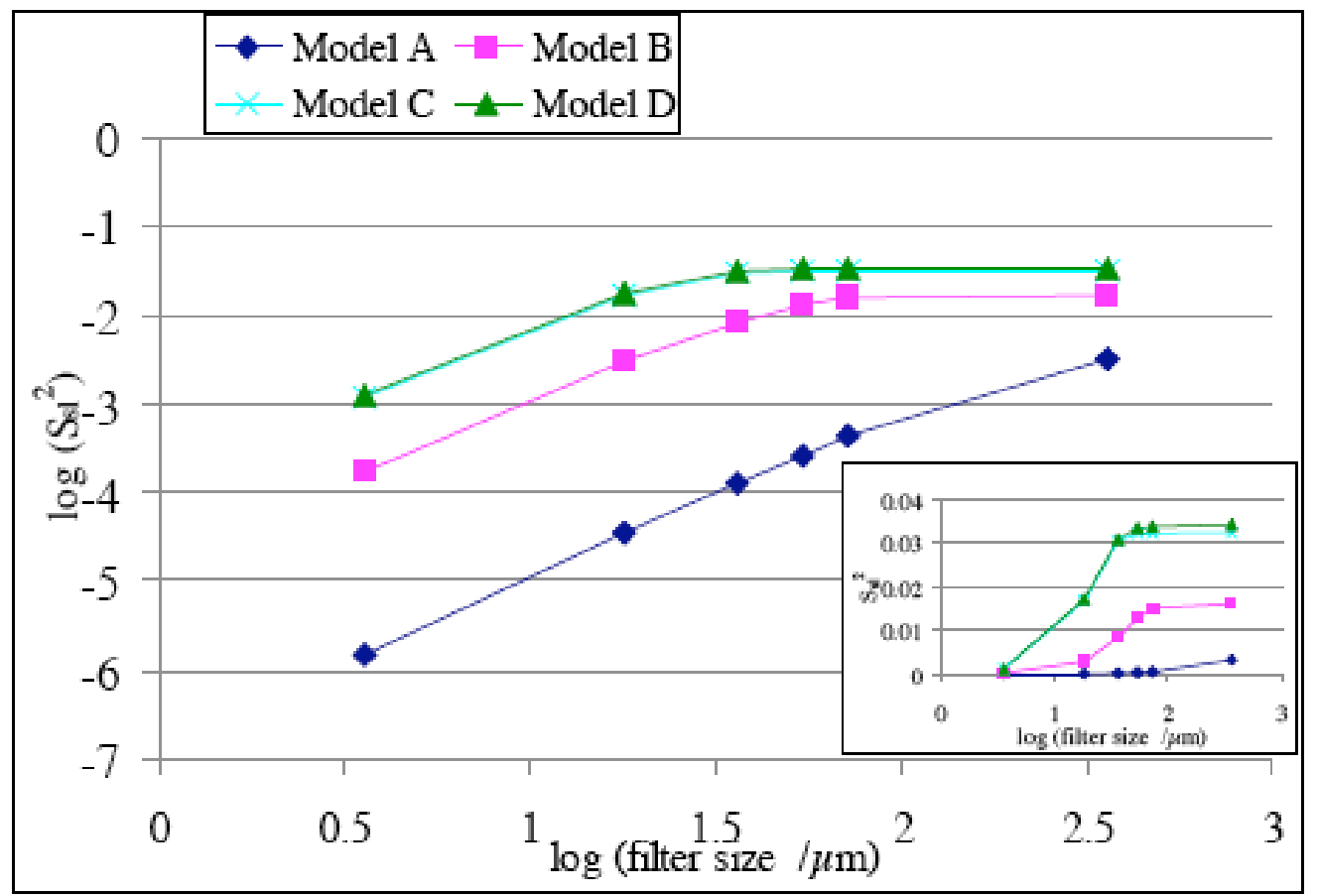

Fig. (13). a) Images of model surfaces. b) Mean slope parameter $\left(\mathrm{S}_{\mathrm{sl}}\right)$ calculated by the plasticity theory on four model surfaces.

surface [16]. At the higher SEM magnifications, the separation between the FB and CB is decreased and at filter sizes below $5 \mu \mathrm{m}$, no separation of the surfaces is obtained. A similar trend was seen for the height parameters of the same surfaces which can be explained by that at higher magnifications, less surface features are present which gives similar results in the parameter values for the FB and $\mathrm{CB}$ surfaces [16].

Much lower mean slope parameter values are obtained for the turned surface compared to the blasted surfaces, which was expected since the topographic analysis showed that the dimensions of the roughness of this surface are smaller than for the blasted surfaces [16]. Another explanation for the lower values is that the turning tracks give poor retention when the bone and surface are sheared in the turning tracks' direction which decreases the overall retention strength. Consistently, the elasticity theory gives lower values than the plasticity theory, the obvious reason for this being that when applying theory of elasticity the bone stresses lie on the linear elastic part of the stress-strain curve while for theory of plasticity all stresses lie on the plastic part of the curve.

The mean slope parameter $v s$ logarithm of filter size plot resembles the plots for the hybrid surface roughness parameters $\mathrm{S}_{\mathrm{dr}}$ (developed interfacial area ratio) and $\mathrm{S}_{\mathrm{dq}}$ (root-mean-square slope of the surface) [16]. The Local model calculates the mean slope parameters and since the $\mathrm{S}_{\mathrm{dq}}$ parameter is the root-mean-square of the same property (calculated according to equation 28) a relationship should exist between the calculated mean slope parameter and $\mathrm{S}_{\mathrm{dq}}$.

$S_{d q}=\sqrt{\frac{1}{l_{x} l_{y}} \int_{0}^{l_{y}} \int_{0}^{l_{x}}\left[\left(\frac{\partial \eta(x, y)}{\partial x}\right)^{2}+\left(\frac{\partial \eta(x, y)}{\partial y}\right)^{2}\right] d x d y}$

where $l_{x}$ and $l_{y}$ are the side lengths of the sampling area and $\eta$ is the height distance from the reference plane $[60,61]$.

The mean slope parameter and $\mathrm{S}_{\mathrm{dq}}$ were plotted in a log$\log$ plot as shown in Fig. (15). As mentioned in previous section, discontinuities were obtained with magnification/ filter size for the mean slope parameters and the hybrid 


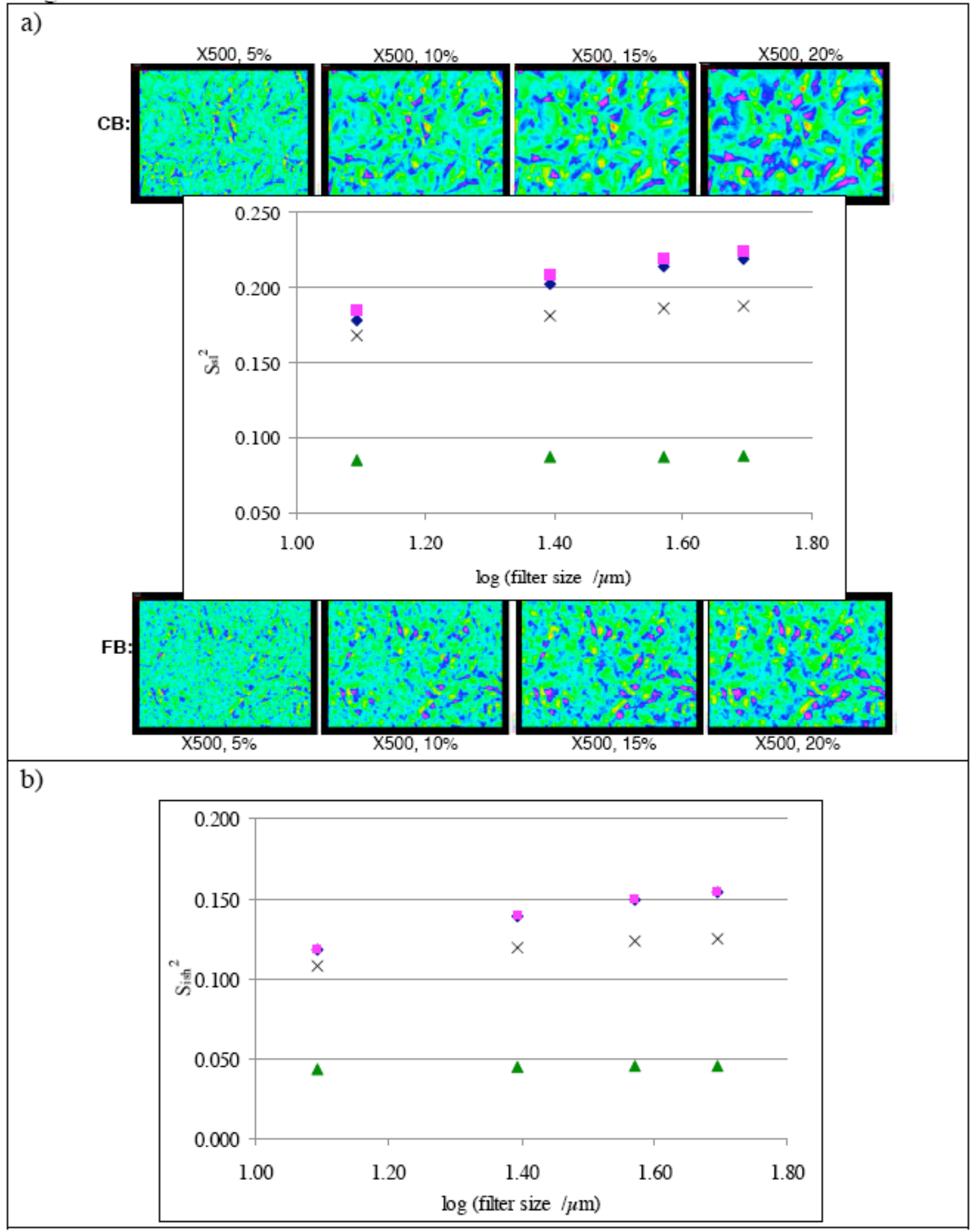

Fig. (14). Mean slope parameter $v s \log$ filter size for the TS, FB, CB, CB+HF surfaces. Calculation performed by a) plasticity theory, b) elasticity theory. In the a) image, filtered $\mathrm{MeX}^{\circledR}$ images are shown after the application of filters on the $\times 500$ SEM magnification and $10 \times 10$ and $3 \times 3 \mu \mathrm{m}$ AFM scan size. These $\mathrm{MeX}^{\circledR}$ images show how much of the surface which is still present after filtering. The depth scale goes from purple which represents the deepest, through blue, green, and yellow up to red which represents the highest points of the surface. Note that the depth scales are all different. $\downarrow=\mathrm{CB}, \boldsymbol{\varpi}=\mathrm{CB}+\mathrm{HF}, \times=\mathrm{FB}, \boldsymbol{\Delta}=\mathrm{TS}$.

parameters. Fig. (15a) shows a linear trend between the mean slope parameter according to plasticity theory and $\mathrm{S}_{\mathrm{dq}}$, revealing that the absolute changes are similar for the plasticity parameter $\left(\mathrm{S}_{\mathrm{sl}}\right)$ and the $\mathrm{S}_{\mathrm{dq}}$. For the elasticity theory, deviations from the linear behaviour are obtained for some magnifications.

The results indicate that the $\mathrm{S}_{\mathrm{dq}}$ parameter can be used to get a rough estimate of the interfacial shear strength induced 


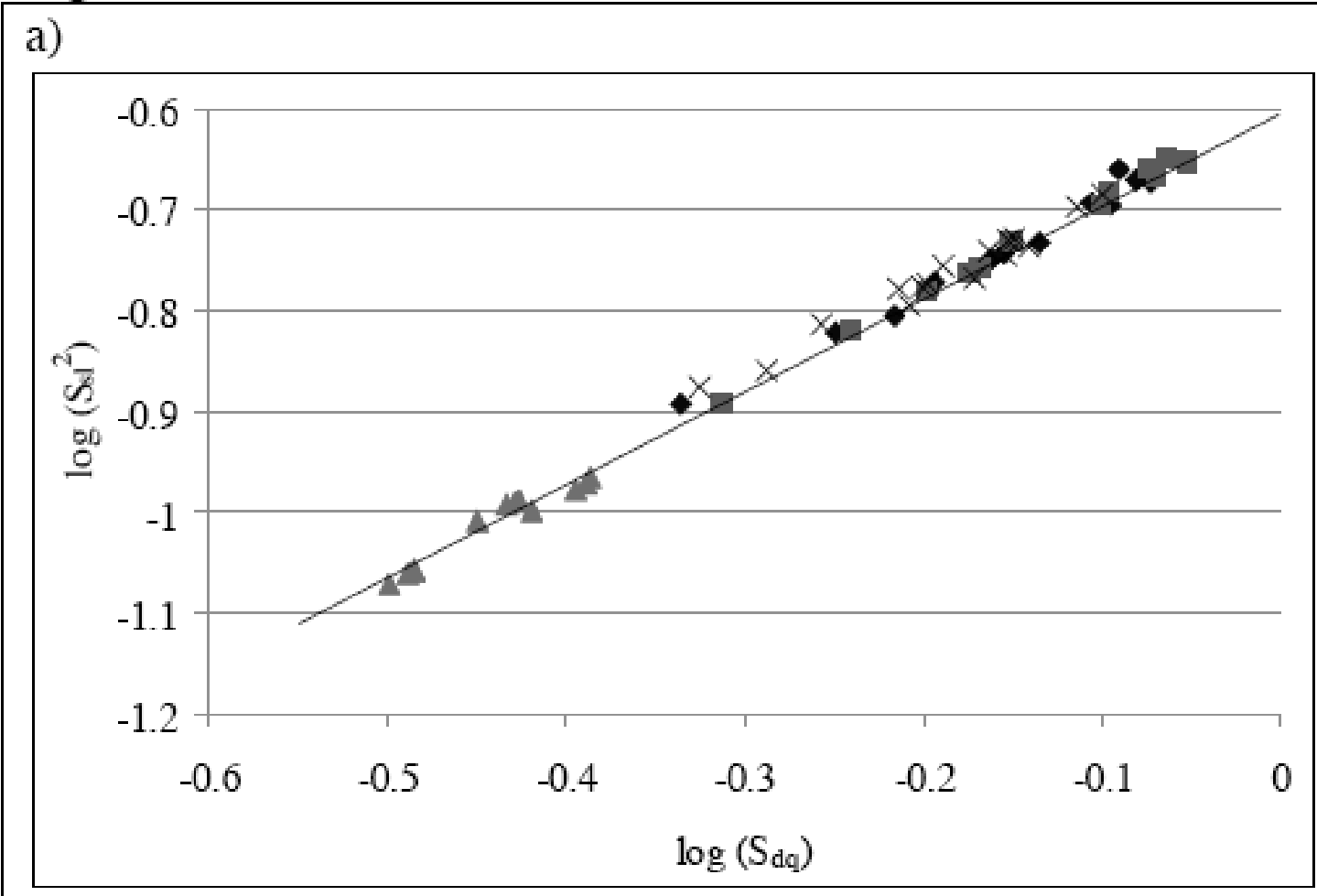

b)

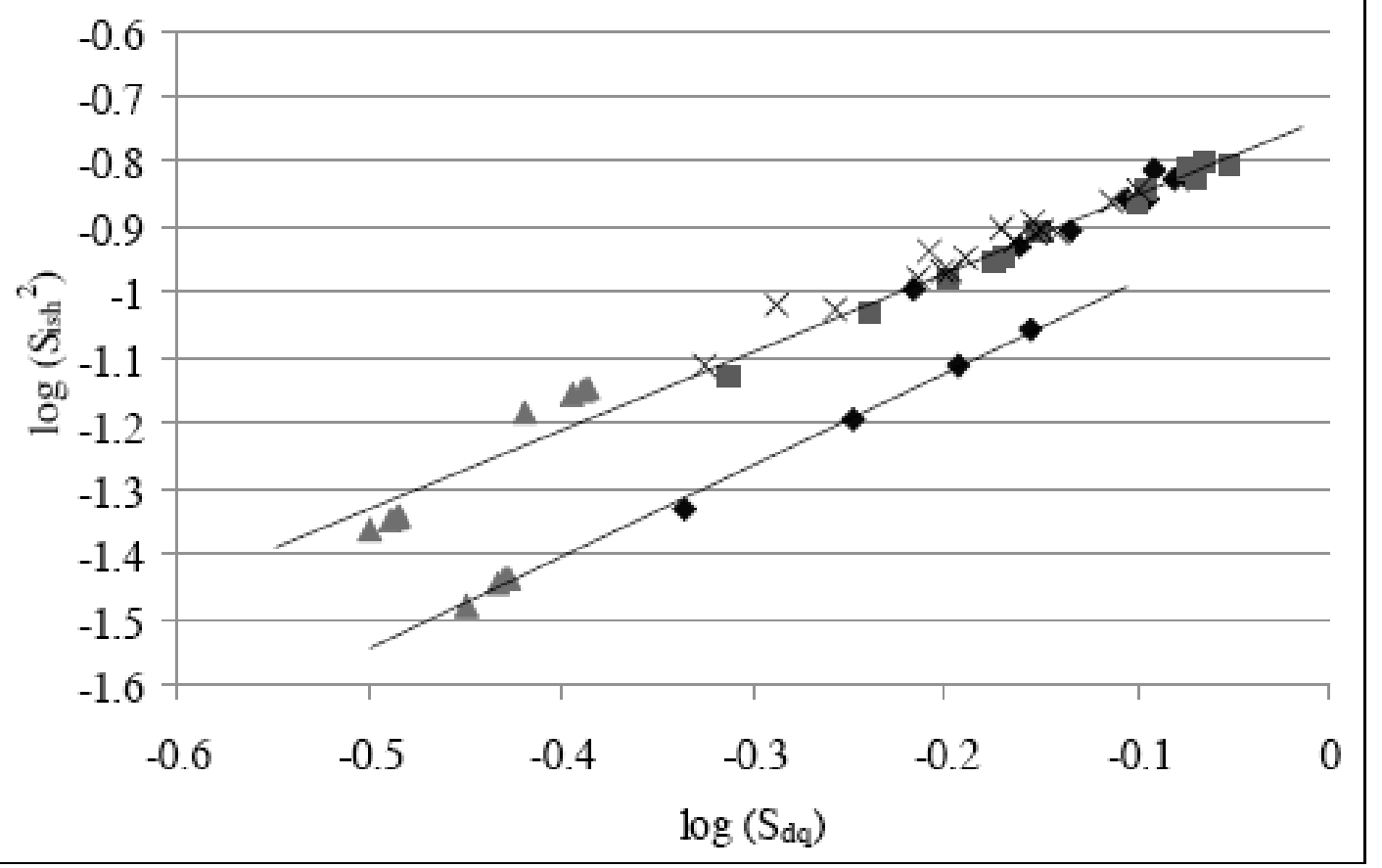

Fig. (15). Log (mean slope parameter) $v s \log \mathrm{S}_{\mathrm{dq}}$ for the $\mathrm{TS}, \mathrm{FB}, \mathrm{CB}$, and $\mathrm{CB}+\mathrm{HF}$ surfaces. Calculation performed by a) theory of plasticity, b) theory of elasticity. $\bullet \mathrm{CB}, \mathbf{a}=\mathrm{CB}+\mathrm{HF}, x=\mathrm{FB}, \boldsymbol{\Delta}=\mathrm{TS}$.

by different surface treatments and that the $S_{\mathrm{dq}}$ parameter correlates better with interfacial shear strength in cases of slow fracture.

\subsubsection{Chemical Modification}

Previous investigations revealed limitations of the 3DSEM technique's ability to separate between the blasted surfaces with and without chemical treatment (CB and $\mathrm{CB}+\mathrm{HF}$ ) with regard to surface roughness parameters [16]. 


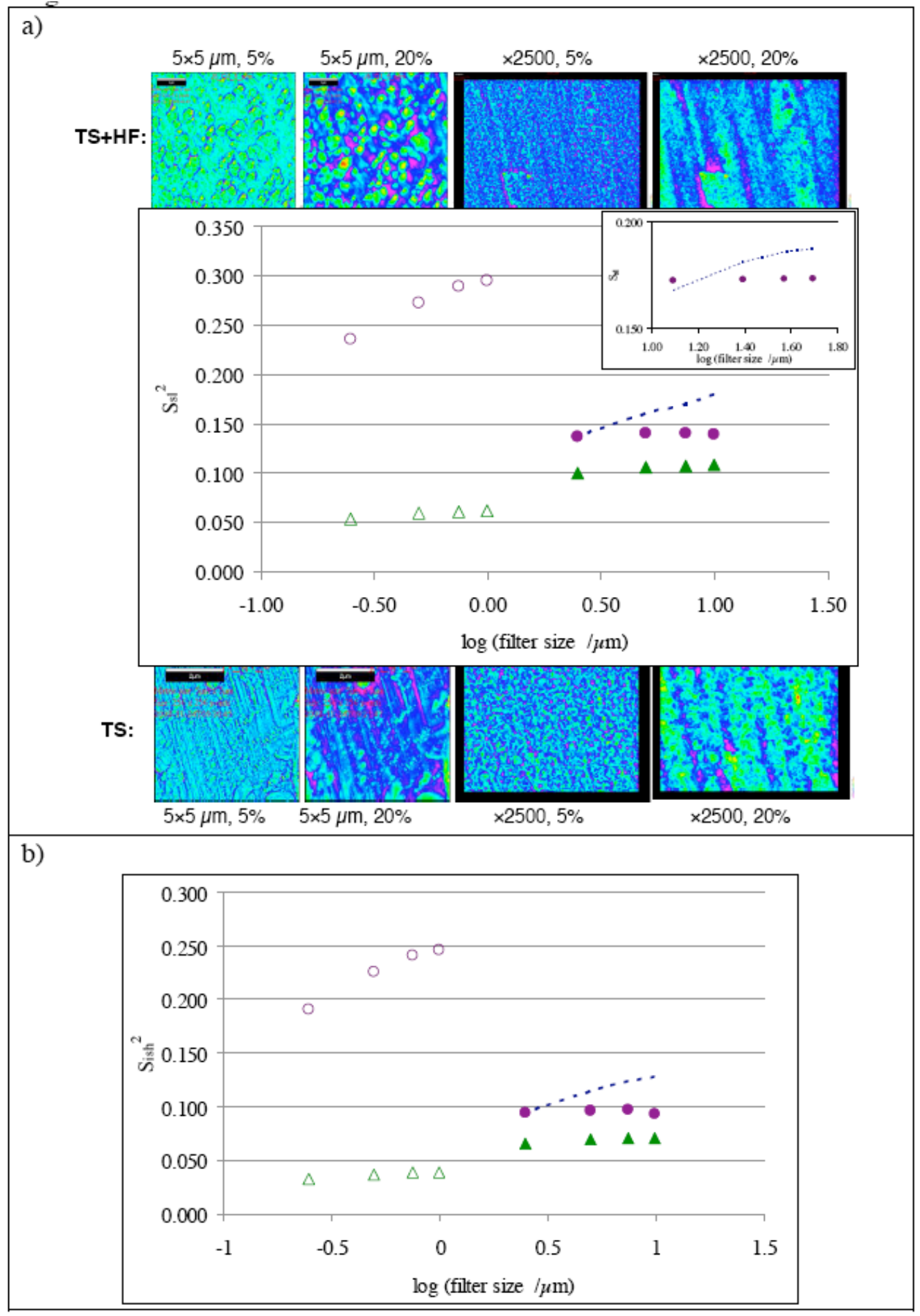

Fig. (16). Mean slope parameter $v s \log$ filter size for the TS and TS+HF surfaces. Calculation performed by a) plasticity theory and b) elasticity theory. In the a) image, filtered $\mathrm{MeX}^{\circledR}$ images are shown where filter sizes of $20 \%$ and $5 \%$ have been applied on the $\times 2500 \mathrm{SEM}$ magnification and $10 \times 10$ and $3 \times 3 \mu \mathrm{m}$ AFM scan size. The depth scale goes from purple which represents the deepest, through blue, green, and yellow up to red which represents the highest points of the surface. Note that the depth scales are all different in the images. $\boldsymbol{\Delta}=\mathrm{TS}$ (3D-SEM range), $\Delta=\mathrm{TS}(\mathrm{AFM}$ range), $\bullet=\mathrm{TS}+\mathrm{HF}$ (3D-SEM range), $\mathrm{o}=\mathrm{TS}+\mathrm{HF}$ (AFM range), ---- = FB

Since the same datafiles were used in this investigation, limitations were expected.

However, somewhat higher mean slope parameter values were obtained for the $\mathrm{CB}+\mathrm{HF}$ surface than the $\mathrm{CB}$ surface when calculated by the plasticity theory, Fig. (14a). No difference was obtained for the theory of elasticity.
The mean slope parameters calculated for the TS and TS + HF surfaces at the 3 D-SEM $\times 2500$ magnification and $5 \times 5 \mu \mathrm{m}$ scan size are plotted in Fig. (16). Similar trends were obtained for both theories but the elasticity theory gives lower values due to the different locations on the bone stress curve. 


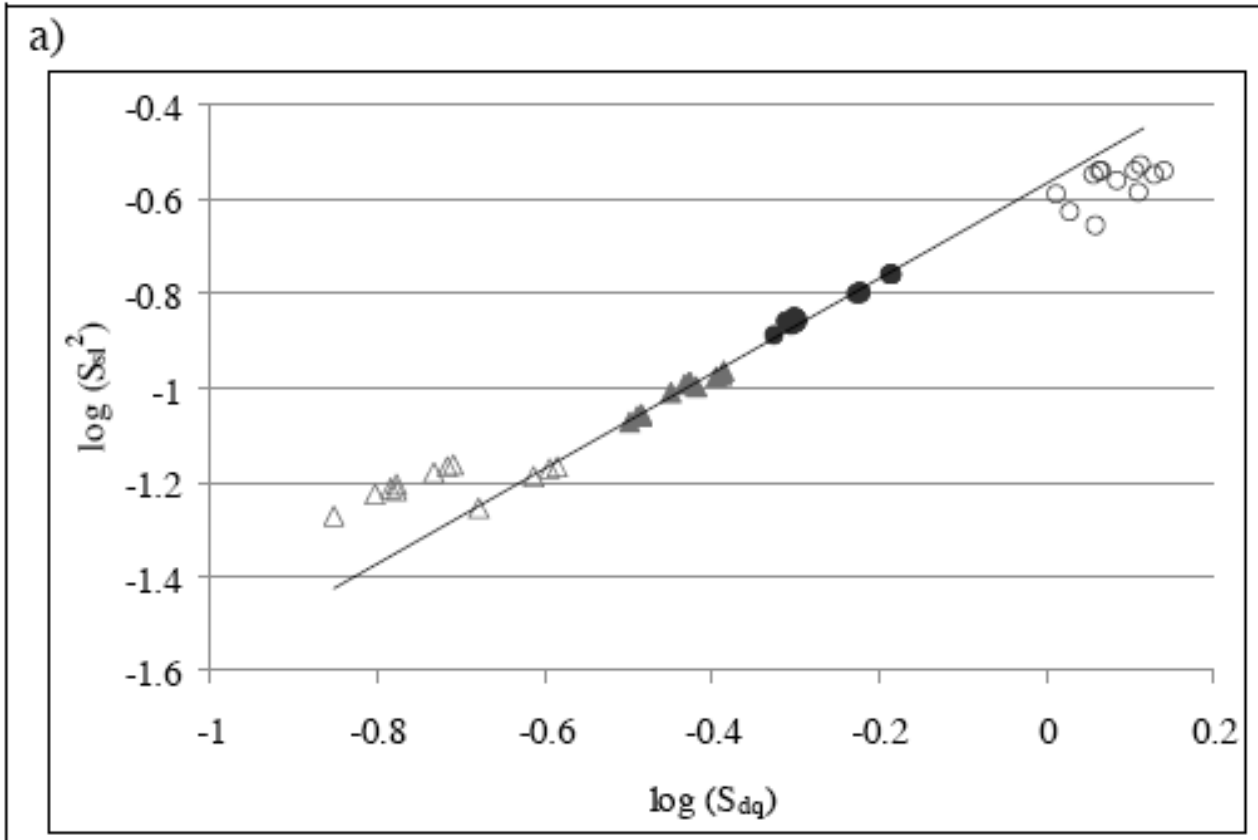

b)

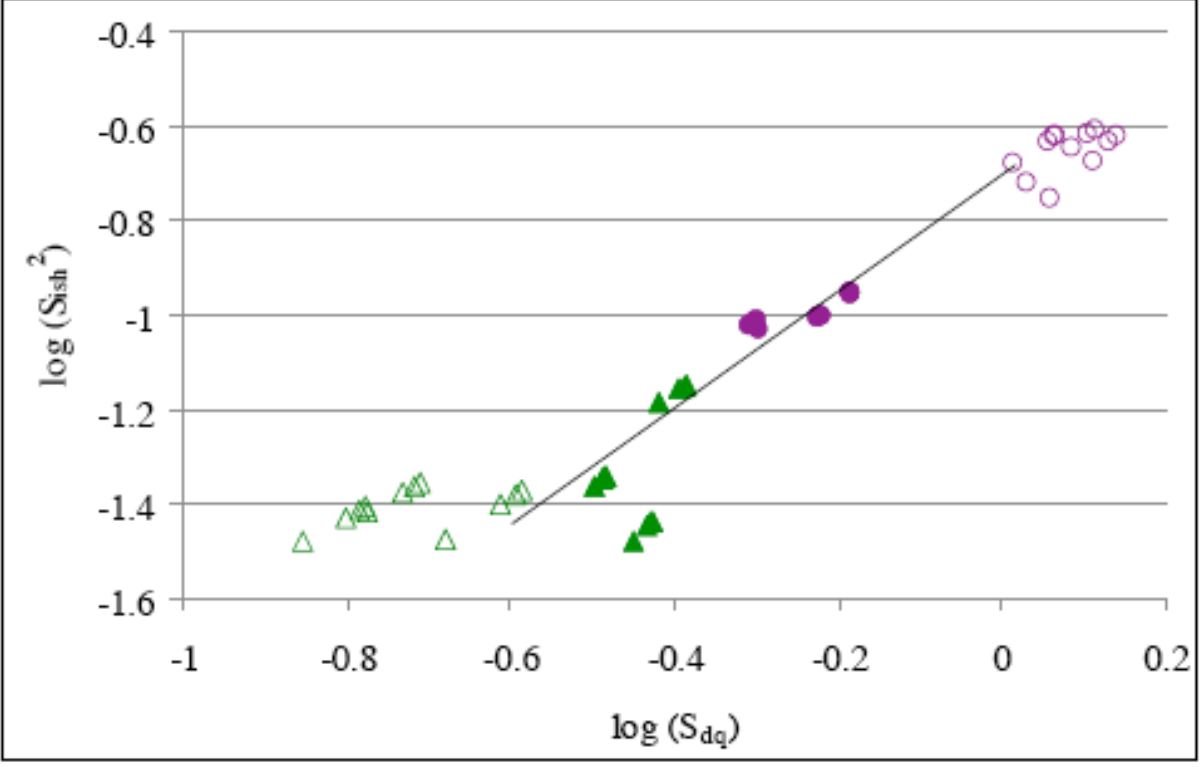

Fig. (17). Log shear strength $v s \log \mathrm{S}_{\mathrm{dq}}$ for the TS, and TS+HF surfaces. Calculated by a) theory of plasticity, b) theory of elasticity. $\boldsymbol{\Delta}=\mathrm{TS}$ (3D-SEM range), $\Delta=\mathrm{TS}$ (AFM range), $\bullet=\mathrm{TS}+\mathrm{HF}$ (3D-SEM range), $\circ=\mathrm{TS}+\mathrm{HF}$ (AFM range).

The HF treatment of the turned surface induced higher values than the untreated one when calculated on both AFM and SEM data. The difference between the TS and TS $+\mathrm{HF}$ surfaces was larger for the AFM data indicating that information from small surface features are to some extent lost in the $3 \mathrm{D}-\mathrm{SEM} / \mathrm{MeX}{ }^{\circledR}$ analysis. This could be due to the smearing effect found for the $\mathrm{MeX}^{\circledR}$ analysis method used [16] which gives effects in higher extent on the SEM analysis due to the larger analysis area and pixel distance [62]. The $\log \left(S_{\mathrm{sl}}\right)-\log \left(\mathrm{S}_{\mathrm{dq}}\right)$ curve, Fig. (17a), reveals straight line behaviour for the plasticity theory calculated on the 3Ddata. However, deviations from the straight line behaviour were obtained for the elasticity theory, Fig. (17b), which is similar to the behaviour found for the physically modified surfaces (Fig. 15).

The results for the turned and HF etched surface falls within the same magnitude as results obtained for the fine blasted surface over the whole the 3D-SEM range (Fig. 16a). A similar trend was seen for the $S_{\mathrm{dq}}$ parameter in a previous study [16] and was explained by that although the FB surface consists of surface features with larger amplitude, the $\mathrm{TS}+\mathrm{HF}$ surface consists of small surface features in larger numbers which results in a similar parameter value according to the parameter definition (Equation 28). The Local model suggests that the FB and TS+HF surface would give similar results in retention strength tests in vivo. 
However, preliminary results using the Global model suggests that this is not the case and that lower interfacial shear strength is received for the TS+HF surface. A correlation between improved retention and higher $S_{a}$ value has also been shown [14, 16], indicating that higher interfacial shear strength would be expected for the FB surface.

\section{CONCLUSIONS}

The aim of this study was to identify and/or develop parameters which can be used to evaluate different topographies' ability to induce interfacial shear strength. A list of assumptions was made to create this model and the validity of it remains to be established. In the derivation of the formulae for interfacial shear strength it was assumed that the bone-to-implant contact was $100 \%$ which normally is not the case [63]. A correction for this can be made by multiplication of the obtained interfacial shear strength value by the bone-to-implant contact ratio [18]. In the derivation of the formulae for interfacial shear strength it was further assumed that the adhesion strength and friction between surface elements and bone were zero. If these factors are also accounted for, a minor increase in interfacial shear strength can be expected.

The theoretical maximum interfacial shear strength equals the shear strength of the surrounding bone. Thus by division of the interfacial shear strength obtained by the above formulae by $\tau_{\text {bf }}$ gives a measure of to what extent this is achieved. The maximum value is 1 .

In a theoretical study it was found that if a change of the surface topography is restricted to scale there is a positive correlation between the $R_{a}$ value, the $2 D$ analogue to the $S_{a}$ value, and the estimated interfacial shear strength [17]. In line with this a literature review showed an increase in removal torque with increasing $S_{a}$ value for blasted implant surfaces [16]. This is in accordance with results in other studies $[9,10,14,64]$. A similar analysis would be desirable for the $S_{\mathrm{dq}}$ parameter. Since this parameter is not commonly used an analysis of the hybrid parameter $S_{\mathrm{dr}}$ was made instead. However, few removal torque studies were found which used the $S_{\mathrm{dr}}$ parameter [11, 65-68] and no uniform correlation seemed to exist.

A linear relationship at the lower filter sizes was found between the $S_{a}$ and $S_{d q}$ parameter when analysing the modelled surfaces shown in Fig. (13a). At the higher filter sizes the relationship gets more complicated since $S_{d q}$ is a derivate. This together with the fact that a correlation between $S_{a}$ and removal torque can be found for certain surfaces, indicates that all topographical factors affecting the retention strength are not included in the Local calculation model. Other factors such as chemical composition [66, 67, 69, 70] and electrical properties [71] have been discussed in terms of influencing the retention strength. The calculated results showed a similar trend to interface shear strength results reported in vivo $[7,11,65,66]$

The local model described in the present paper has some inherent limitations, for example in the derivation of the formulae for interfacial shear strength it was assumed that the bone-to-implant contact was $100 \%$. A correction for the fact that this is normally not the case [63] can be made by multiplication of the interfacial shear strength value by an assumed bone-to-implant contact ratio. It was further assumed that the mechanical properties of the bone were uniform within a zone containing the roughness considered, which is a simplification. In a forthcoming paper further development of the Local model will be given where, in addition to the mean slope, also the amplitude of the roughness, the bone anatomy, the implant design, and the modulus of elasticity and Poisson's ratio of the implant material are considered. This model is called the Global model.

\section{ACKNOWLEDGEMENT}

Financial support from the Swedish Research Council (2005-21028-35344-27) is gratefully acknowledged.

\section{LIST OF SYMBOLS}

\begin{tabular}{|c|c|c|}
\hline Symbol & Explanation & Unit \\
\hline A & Area & {$\left[\mathrm{m}^{2}\right]$} \\
\hline $\mathrm{A}_{\mathrm{sh}}$ & $\begin{array}{l}\text { Area where the failure mechanism is } \\
\text { expected to be shear fracture of bone } \\
\text { plugs protruding into roughness pits }\end{array}$ & {$\left[\mathrm{m}^{2}\right]$} \\
\hline $\mathrm{f}_{\mathrm{pe}}$ & Pit effectivity factor & - \\
\hline $\mathrm{f}_{\mathrm{pd}}$ & Pit density factor & - \\
\hline $\mathrm{F}_{\mathrm{c}}$ & $\begin{array}{l}\text { Compressive force, induced by the } \\
\text { load }\end{array}$ & {$[\mathrm{N}]$} \\
\hline $\mathrm{F}_{\mathrm{cf}}$ & Fracture force in compression & {$[\mathrm{N}]$} \\
\hline $\mathrm{F}_{\mathrm{c}}^{\prime \prime}$ & $\begin{array}{l}\text { Component of compressive force in } \\
\text { parallel with the implant surface }\end{array}$ & {$[\mathrm{N}]$} \\
\hline $\mathrm{F}_{\mathrm{c}}^{\mathrm{L}}$ & $\begin{array}{l}\text { Component of compressive force } \\
\text { directed perpendicularly to the } \\
\text { implant surface }\end{array}$ & {$[\mathrm{N}]$} \\
\hline $\mathrm{F}_{\mathrm{i}}$ & $\begin{array}{l}\text { Implant force at fracture directed in } \\
\text { parallel with the implant surface }\end{array}$ & {$[\mathrm{N}]$} \\
\hline $\mathrm{F}_{\mathrm{sh}}$ & Shear force, induced by the load & {$[\mathrm{N}]$} \\
\hline $\mathrm{F}_{\mathrm{shf}}$ & Fracture force in shear & {$[\mathrm{N}]$} \\
\hline $\mathrm{I}_{\mathrm{sh}}{ }^{\mathrm{p}}$ & $\begin{array}{l}\text { Interfacial shear strength according } \\
\text { to theory of plasticity }\end{array}$ & {$[\mathrm{MPa}]$} \\
\hline $\mathrm{I}_{\mathrm{sh}}{ }^{\mathrm{e}}$ & $\begin{array}{l}\text { Interfacial shear strength according } \\
\text { to theory of elasticity }\end{array}$ & {$[\mathrm{MPa}]$} \\
\hline $\mathrm{k}_{1}$ & $\begin{array}{l}\text { Bone compression corresponding to } \\
\text { the upper end of the elastic phase of } \\
\text { the stress-strain curve }\end{array}$ & {$[\mathrm{m}]$} \\
\hline $\mathrm{k}_{2}$ & Coefficient for pit spacing & - \\
\hline $\mathrm{k}_{3}$ & Coefficient for cross-sectional shape & - \\
\hline $\mathrm{k}_{4}$ & Coefficient for cross-sectional shape & - \\
\hline
\end{tabular}




\begin{tabular}{|c|c|c|}
\hline $\mathrm{N}$ & $\begin{array}{l}\text { Number of surface elements } \\
\text { considered }\end{array}$ & \\
\hline $\mathrm{R}_{\text {ish }}$ & $\begin{array}{l}\text { 2D surface roughness parameter } \\
\text { which mirrors the interfacial shear } \\
\text { strength according to theory of } \\
\text { elasticity }\end{array}$ & \\
\hline $\mathrm{R}_{\mathrm{sl}}$ & $\begin{array}{l}\text { The } 2 \mathrm{D} \text { surface roughness parameter } \\
\text { mean slope }\end{array}$ & - \\
\hline $\mathrm{S}_{\mathrm{sl}}^{1}$ & $\begin{array}{l}\text { One definition of a } 3 \mathrm{D} \text { surface } \\
\text { roughness parameter mean slope }\end{array}$ & \\
\hline$S^{2}{ }_{s l}$ & $\begin{array}{l}\text { Alternative definition of a } 3 \mathrm{D} \text { surface } \\
\text { roughness parameter mean slope }\end{array}$ & \\
\hline $\mathrm{S}_{\text {ish }}$ & $\begin{array}{l}\text { 3D surface roughness parameter } \\
\text { which mirrors the interfacial shear } \\
\text { strength according to theory of } \\
\text { elasticity }\end{array}$ & - \\
\hline$\Delta \mathrm{x}$ & $\begin{array}{l}\text { Length of surface element projected } \\
\text { on a horizontal plane. Defined as } \\
\text { distance between pixels }\end{array}$ & {$[\mathrm{m}]$} \\
\hline$\Delta y$ & $\begin{array}{l}\text { Width of surface element projected } \\
\text { on a horizontal plane. Defined as } \\
\text { distance between pixels }\end{array}$ & {$[\mathrm{m}]$} \\
\hline$\alpha$ & Inclination angle of surface element & $\circ$ \\
\hline$\alpha_{\max }$ & $\begin{array}{l}\text { Maximum slope of the surface } \\
\text { profile }\end{array}$ & 。 \\
\hline$\sigma_{\text {bcf }}$ & Compressive strength of bone & [MPa] \\
\hline$\tau$ & Shear stress & {$[\mathrm{MPa}]$} \\
\hline$\tau_{\mathrm{bf}}$ & Shear strength of bone & [MPa] \\
\hline
\end{tabular}

\section{REFERENCES}

[1] Brunski JB. Biomechanics of oral implants: Future research directions. J Dent Educ 1988; 525: 775-87.

[2] Perren SM, Huggler A, Russenberger M, et al. The reaction of cortical bone to compression. Acta Orthop Scand Suppl 1969; 125: 19-29.

[3] Bobyn JD, Pillar RM, Cameron HU, Weatherly GC, Kent GM. The effect of porous surface configuration on the tensile strength of fixation of implants by bone ingrowth. Clin Orthop Relat Res 1980; 149: 291-8.

[4] Ronold HJ, Ellingsen JE, Lyngstadaas SP. Tensile force testing of optimized coin-shaped titanium implant attachment kinetics in the rabbit tibiae. J Mater Sci Mater Med 2003; 14: 843-9.

[5] Lamolle SF, Monjo M, Lyngstadaas SP, Ellingsen JE, Haugen HJ. Titanium implant surface modification by cathodic reduction in hydrofluoric acid: surface characterization and in vivo performance. J Biomed Mater Res Part A 2009; 88A(3): 581-8.

[6] Rubo de Rezende ML, Johansson CB. Quantitative bone tissue response to commercially pure titanium implants. J Mater Sci Mater Med 1993; 4: 233-9.

[7] Gotfredsen K, Wennerberg A, Johansson C, Skovgaard LT, Hjoerting-Hansen E. Anchorage of $\mathrm{TiO}_{2}$-blasted, HA-coated, and machined implants: An experimental study with rabbits. J Biomed Mater Res 1995; 29(10): 1223-31.
Wennerberg A, Albrektsson T, Andersson B, Krol JJ. A histomorphometric and removal torque study of screw-shaped titanium implants with three different surface topographies. Clin Oral Implants Res 1995; 6(1): 24-30.

[9] Wennerberg A, Albrektsson T, Johansson C, Andersson B. Experimental study of turned and grit-blasted screw-shaped implants with special emphasis on effects of blasting material and surface topography. Biomaterials 1996; 17(1): 15-22.

[10] Wennerberg A, Albrektsson T, Lausmaa J. Torque and histomorphometric evaluation of c.p. titanium screws blasted with 25- and 75- $\mu \mathrm{m}$-sized particles of $\mathrm{Al}_{2} \mathrm{O}_{3}$. J Biomed Mater Res 1996; 30(2): 251-60.

[11] Ellingsen JE, Johansson CB, Wennerberg A, Holmén A. Improved retention and bone-implant contact with fluoride-modified titanium implants. Int J Oral Maxillofac Implants 2004; 19: 659-66.

[12] Arvidsson A, Sater BA, Wennerberg A. The role of functional parameters for topographical characterization of bone-anchored implants. Clin Implant Dent Relat Res 2006; 8(2): 70-6.

[13] Shalabi MM, Gortemaker A, Van't Hof MA, Jansen JA, Creugers NHJ. Implant surface roughness and bone healing: a systematic review. J Dent Res 2006; 85(6): 496-500.

[14] Wennerberg A, Albrektsson T. Suggested guidelines for the topographic evaluation of implant surfaces. Int J Oral Maxillofac Implants 2000; 15(3): 331-44.

[15] Hansson S, Hansson KN. The effect of limited lateral resolution in the measurement of implant surface roughness: a computer simulation. J Biomed Mater Res Part A 2005; 75A(2): 472-7.

[16] Löberg J, Petersson I, Hansson S, Ahlberg E. Surface characterisation of titanium dental implants. I: critical assessment of surface roughness parameters. 2009; submitted.

[17] Hansson S. Surface roughness parameters as predictors of anchorage strength in bone: a critical analysis. J Biomech 2000; 33(10): 1297-303.

[18] Hansson S, Norton M. The relation between surface roughness and interfacial shear strength for bone-anchored implants. A mathematical model. J Biomech 1999; 32(8): 829-36.

[19] Albrektsson T, Brånemark PI, Hansson HA, Ivarsson B, Jönsson U. Ultrastructural analysis of the interface zone of titanium and gold implants. In: Albrektsson T, Lee A, Branemark PI, Eds. Advances in biomaterials. Chichester: Wiley 1982; pp. 167-77.

[20] Albrektsson T, Hansson HA. An ultrastructural characterization of the interface between bone and sputtered titanium or stainless steel surfaces. Biomaterials 1986; 7(3): 201-05.

[21] Albrektsson T, Hansson HA, Ivarsson B. Interface analysis of titanium and zirconium bone implants. Biomaterials 1985; 6(2): 97101.

[22] Hansson HA, Albrektsson T, Brånemark PI. Structural aspects of the interface between tissue and titanium implants. J Prosthet Dent 1983; 50(1): 108-13.

[23] Linder L, Albrektsson T, Brånemark PI, et al. Electron microscopic analysis of the bone-titanium interface. Acta Orthop Scand 1983; 54(1): 45-52.

[24] Johansson C, Lausmaa J, Ask M, Hansson HA, Albrektsson T. Ultrastructural differences of the interface zone between bone and Ti 6Al 4V or commercially pure titanium. J Biomed Eng 1989; 11(1): 3-8.

[25] Johansson CB, Hansson HA, Albrektsson T. Qualitative interfacial study between bone and tantalum, niobium or commercially pure titanium. Biomaterials 1990; 11(4): 277-80.

[26] Sennerby L, Ericson LE, Thomsen P, Lekholm U, Astrand P. Structure of the bone-titanium interface in retrieved clinical oral implants. Clin Oral Implants Res 1991; 2(3): 103-11.

[27] Sennerby L, Thomsen P, Ericson LE. Ultrastructure of the bonetitanium interface in rabbits. J Mater Sci: Mater Med 1992; 3(4): 262-71.

[28] Sennerby L, Thomsen P, Ericson LE. Early tissue response to titanium implants inserted in rabbit cortical bone. Part II: Ultrastructural observations. J Mater Sci: Mater Med 1993; 4(5): 494-502.

[29] De Bruijn JD, van Blitterswijk CA, Davies JE. Initial bone matrix formation at the hydroxyapatite interface in vivo. J Biomed Mater Res 1995; 29(1): 89-99.

[30] De Lange GL, de Putter C, de Wijs FL. Histological and ultrastructural appearance of the hydroxyapatite-bone interface. J Biomed Mater Res 1990; 24(7): 829-45. 
[31] Listgarten MA, Buser D, Steinemann SG, Donath K, Lang NP, Weber HP. Light and transmission electron microscopy of the intact interfaces between non-submerged titanium-coated epoxy resin implants and bone or gingiva. J Dent Res 1992; 71(2): 36471.

[32] Steflik DE, Hanes PJ, Sisk AL, Parr GR, Song MJ, Lake FT, et al. Transmission electron microscopic and high voltage electron microscopic observations of the bone and osteocyte activity adjacent to unloaded dental implants placed in dogs. J Periodontol 1992; 63(5): 443-52.

[33] Steflik DE, Sisk AL, Parr GR, et al. Osteogenesis at the dental implant interface: High-voltage electron microscopic and conventional transmission electron microscopic observations. J Biomed Mater Res 1993; 27(6): 791-800.

[34] Piattelli A, Trisi P, Romasco N, Emanuelli M. Histologic analysis of a screw implant retrieved from man: influence of early loading and primary stability. J Oral Implantol 1993; 19(4): 303-06.

[35] Roux W. Der Kampf der Theile im Organismus. Ein Beitrag zur Vervollständigung der mechanischen Zweckmässigkeitslehre. Leipzig: Verlag von Wilhelm Engelmann 1881.

[36] Stanford CM, Brand RA. Toward an understanding of implant occlusion and strain adaptive bone modeling and remodeling. $\mathrm{J}$ Prosthet Dent 1999; 443-52.

[37] Warden SJ, Hurst JA, Sanders MS, Turner CH, Burr DB, Li J. Bone adaptation to a mechanical loading program significantly increases skeletal fatigue resistance. J Bone Miner Res 2005; 20: 809-16.

[38] Rubin C, Lanyon LE. Regulation of bone formation by applied dynamic loads. J Bone Joint Surg 1984; 66: 397-402.

[39] Rubin CT, Sommerfeldt DW, Judex S, Qin YX. Inhibition of osteopenia by low magnitude, high-frequency mechanical stimuli. Drug Discov Today 2001; 6: 848-58.

[40] Mosley JR, Lanyon LE. Strain rate as a controlling influence on adaptive modeling in response to dynamic loading of the ulna in growing male rats. Bone 1998; 23(4): 313-8.

[41] Iqbal J, Zaidi M. Molecular regulation of mechanotransduction. Biochem Biophys Res Commun 2005; 328: 751-5.

[42] Klein-Nulend J, van der Plas A, Semeins CM, Ajubi NE, Frangos JA, Nijweide PJ, et al. Sensitivity of osteocytes to biomechanical stress in vitro. FASEB J 1995; 9: 441-5.

[43] Vogel V, Sheetz M. Local force and geometry sensing regulate cell function. Nat Rev Mol Cell Biol 2006; 7: 265-75.

[44] Schwartz MA. The force is with us. Science 2009; 323: 588-9.

[45] Brunette DM, Kzakbaznejad A, Takekawa M, et al. Improving the bio-implant interface by controlling cell behaviour using surface topography. In: Ellingsen JE, Lyngstadaas SP, Eds. Bio-implant interface. Boca Raton: CRC Press 2003; pp. 103-21.

[46] Lossdoerfer S, Schwartz Z, Wang L, et al. Microrough implant surface topographies increase osteogenesis by reducing osteoclast formation and activity. J Biomed Mater Res Part A 2004; 70A(3): $361-9$.

[47] Haberstroh KM. Hope for the short-term use of nanorough metallic implant formulations in the clinical arena. Nanomedicine 2006; 1(3): $355-8$.

[48] Currey JD. Differences in the tensile strength of bone of different histological types. J Anat 1959; 93(1): 87-95.

[49] Currey JD. The mechanical consequences of variation in the mineral content of bone. J Biomech 1969; 2(1): 1-11.

[50] Vose GP. The relation of microscopic mineralization to intrinsic bone strength. Anat Rec 1962; 144: 31-6.
[51] Young J. The life of mammals. Oxford: Oxford University Press 1957.

[52] Sylven B. The ground substance of connective tissue and cartilage. In: Bourne G, Ed. The biochemistry and physiology of bone. New York: Academic Press 1956; pp. 53-80.

[53] Zioupos P, Gresle M, Winwood K. Fatigue strength of human cortical bone: age, physical, and material heterogeneity effects. J Biomed Mater Res Part A 2008; 86A(3): 627-36.

[54] McElhaney JH. Dynamic response of bone and muscle tissue. J Appl Physiol 1966; 21(4): 1231-6.

[55] Rho J-Y, Kuhn-Spearing L, Zioupos P. Mechanical properties and the hierarchical structure of bone. Med Eng Phys 1998; 20: 92-102.

[56] Chakrabarty J. Theory of plasticity. $3^{\text {rd }}$ ed. Burlington: Elsevier Butterworth-Heinemann 2006

[57] Timoshenko SP, Goodier JN. Theory of elasticity. $3^{\text {rd }}$ ed. Singapore: McGraw-Hill Book Co. 1982.

[58] MeX. 5.0 ed. Alicona Imaging Gmbh, Graz.

[59] Albrektsson T, Wennerberg A. Oral implant surfaces. Part 1: Review focusing on topographic and chemical properties of different surfaces and in vivo responses to them. Int J Prosthodont 2004; 17(5): 536-43.

[60] Dong WP, Sullivan PJ, Stout KJ. Comprehensive study of parameters for characterizing three-dimensional surface topography. IV: Parameters for characterizing spatial and hybrid properties. Wear 1994; 178(1-2): 45-60.

[61] Stout KJ, Ed. Development of methods for the characterisation of roughness in three dimensions. London: Penton Press 2000

[62] Chauvy PF, Madore C, Landolt D. Variable length scale analysis of surface topography: characterization of titanium surfaces for biomedical applications. Surf Coat Technol 1998; 110: 48-56.

[63] Buser D, Schenk RK, Steinemann S, Fiorellini JP, Fox CH, Stich $\mathrm{H}$. Influence of surface characteristics on bone integration of titanium implants. A histomorphometric study in miniature pigs. J Biomed Mater Res 1991; 25(7): 889-902.

[64] Wennerberg A. On Surface Roughness and Implant Incorporation. PhD thesis. Göteborg: Göteborg University 1996.

[65] Johansson CB, Wennerberg A, Boström-Junemo K, Holmen A, Hansson $\mathrm{S}$. In vivo comparison of $\mathrm{TiO}_{2}$ blasted- and fluoride modified implants in rabbit bone. 7th World Biomaterials Congress, Sydney 2004.

[66] Meirelles L, Currie F, Jacobsson M, Albrektsson T, Wennerberg A. The effect of chemical and nanotopographical modifications on the early stages of osseointegration. Int $\mathrm{J}$ Oral Maxillofac Implants 2008; 23(4): 641-7.

[67] Sul Y-T, Johansson CB, Jeong Y, Wennerberg A, Albrektsson T. Resonance frequency and removal torque analysis of implants with turned and anodized surface oxides. Clin Oral Implants Res 2002; 13(3): $252-9$

[68] Wennerberg A, Ektessabi A, Albrektsson T, Johansson C, Andersson B. A 1-year follow-up of implants of differing surface roughness placed in rabbit bone. Int $\mathrm{J}$ Oral Maxillofac Implants 1997; 12(4): 486-94.

[69] Sul Y-T, Jeong Y, Johansson C, Albrektsson T. Oxidized, bioactive implants are rapidly and strongly integrated in bone. Part 1 : experimental implants. Clin Oral Implants Res 2006; 17(5): 521-6.

[70] Sul Y-T, Johansson C, Byon E, Albrektsson T. The bone response of oxidized bioactive and non-bioactive titanium implants. Biomaterials 2005; 26(33): 6720-30.

[71] Petersson I, Löberg J, Fredriksson A, Ahlberg E. Semi-conducting properties of titanium dioxide surfaces on titanium implants. Biomaterials 2009; 30(27): 4471-79.

This is an open access article licensed under the terms of the Creative Commons Attribution Non-Commercial License (http://creativecommons.org/licenses/bync/3.0/) which permits unrestricted, non-commercial use, distribution and reproduction in any medium, provided the work is properly cited. 